Portland State University

PDXScholar

1986

\title{
Modification of the western approach to intercultural communication for the Japanese context
}

Eiko Tai

Portland State University

Follow this and additional works at: https://pdxscholar.library.pdx.edu/open_access_etds

Part of the International and Intercultural Communication Commons, and the Japanese Studies Commons

Let us know how access to this document benefits you.

\section{Recommended Citation}

Tai, Eiko, "Modification of the western approach to intercultural communication for the Japanese context" (1986). Dissertations and Theses. Paper 3684.

https://doi.org/10.15760/etd.5568

This Thesis is brought to you for free and open access. It has been accepted for inclusion in Dissertations and Theses by an authorized administrator of PDXScholar. Please contact us if we can make this document more accessible: pdxscholar@pdx.edu. 
AN ABSTRACT OF THE THESIS OF Eiko Tai for the Master of Arts in Speech Communication presented November 22, 1986.

Title: Modification of the western Approach to Intercultural

Communication for the Japanese Context.

APPROVED BY MEMBERS OF THE THESIS COMMITEE:

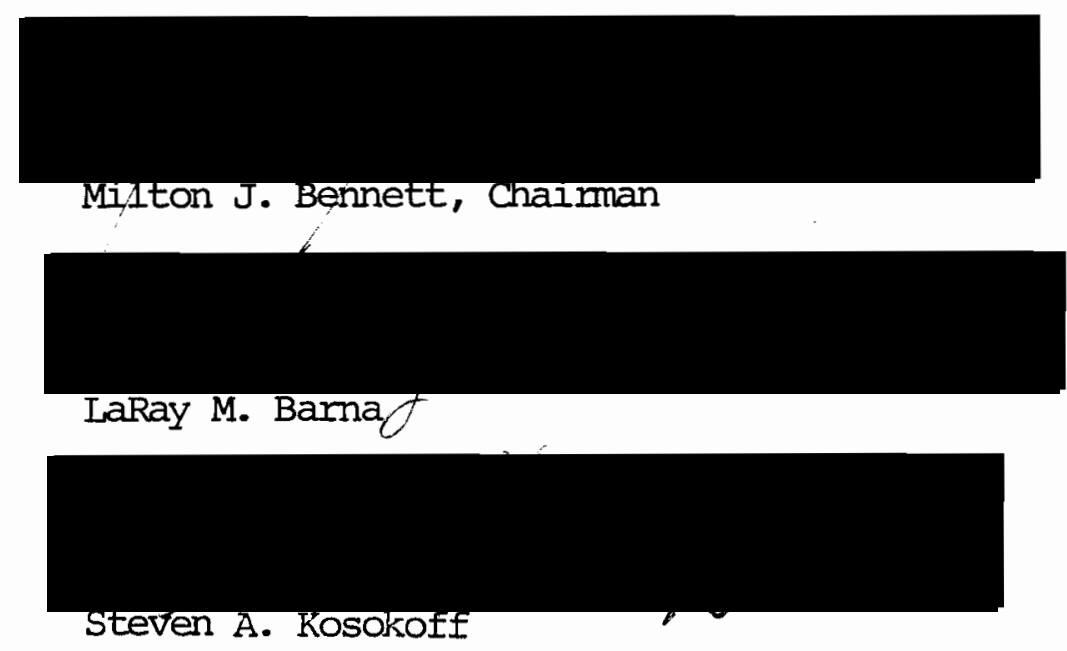

The field of intercultural communication has recently been introduced to Japan from the United States. The theories and concepts of this field have been developed based on Western social sciences, and they are likely to be culture-bound. This thesis investigates the possibility that modifying Western ideas in the field of intercultural communication would make the study of this subject more effective for Japanese learners.

First, the literature on intercultural communication in the United States is reviewed. The main ideas and notions of the field are presented 
as the Western approach to intercultural communication. This approach is described in terms of two areas: the sources of problems in intercultural communication as perceived by Westerners; and Western ideas on how to improve intercultural communication.

Then, the literature on Japanese people and culture is surveyed to identify the Japanese tendencies and attitudes which might interfere with successful intercultural communication. Five potential difficulties of Japanese were identified. They are: exclusionary attitudes toward foreigners, racial chauvinism, tendency to rank cultures, lack of absolute principles, and the use of formalized communication or the imposition of their intimate communication style for intercultural interaction.

The Japanese factors are compared and contrasted with the sources of intercultural problems in the Western approach. Among the Western problems, the assumption of similarities in the behavioral aspect, ethnocentrism, stereotypes and prejudice were found to be relevant to Japanese. The melting pot view and the assumption of fundamental human similarities were found to be irrelevant to Japanese. The difficulties peculiar to Japanese are their exclusionary attitudes to foreigners and their lack of absolute principles.

Next, Japanese ways to improve intercultural communication are explored. This was done by modifying Western strategies for effective intercultural communication. The first step Japanese would need to take toward successful intercultural interaction is to realize that intercultural communication can be studied and improved. Four notions and three communication skills adapted from the Western approach are prescribed. The four notions are: reoognizing cultural differences, 
cultural self-awareness, cultural relativism and the idea of a multicultural person. The three skills are: low-context communication, empathy and nonjudgmental attitudes. The skill of low-context communication was added for Japanese while the skill of the tolerance of ambiguity in the Western approach was regarded irrelevant for Japanese and was eliminated. Applications of the modification to training are demonstrated. 


\title{
MODIFICATION OF THE WESTERN APPROACH \\ TO INIERCULTURAL COMMUNICATION \\ FOR THE JAPANESE CONTEXT
}

by

EIKO TAI

\author{
A thesis submitted in partial fulfillment of the \\ requirements for the degree of \\ MASTER OF ARTS \\ in \\ SPEECH COMMUNICATION
}

Portland State University 
TO THE OFFICE OF GRADUATE STUDIES AND RESEARCH:

The members of the Cammittee approve the thesis of Eiko Tai presented November 22, 1986.
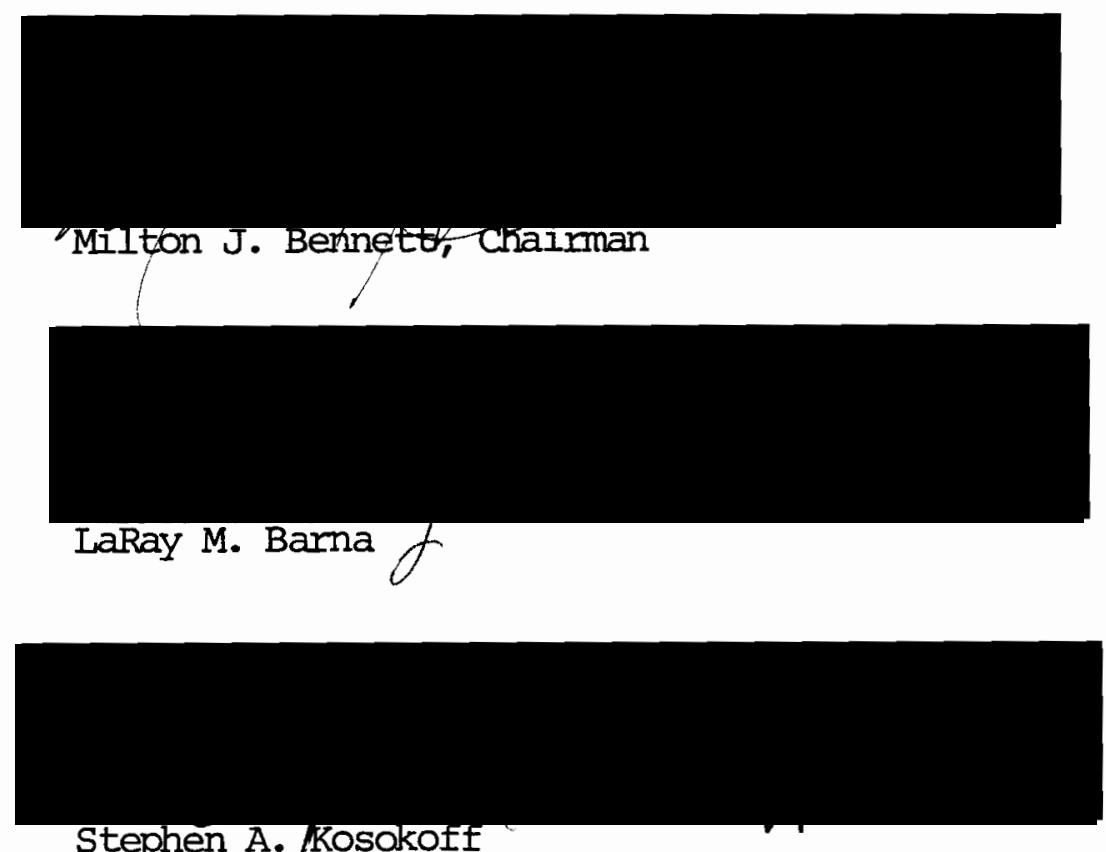

Stephen A. KKosokofł

APPROVED

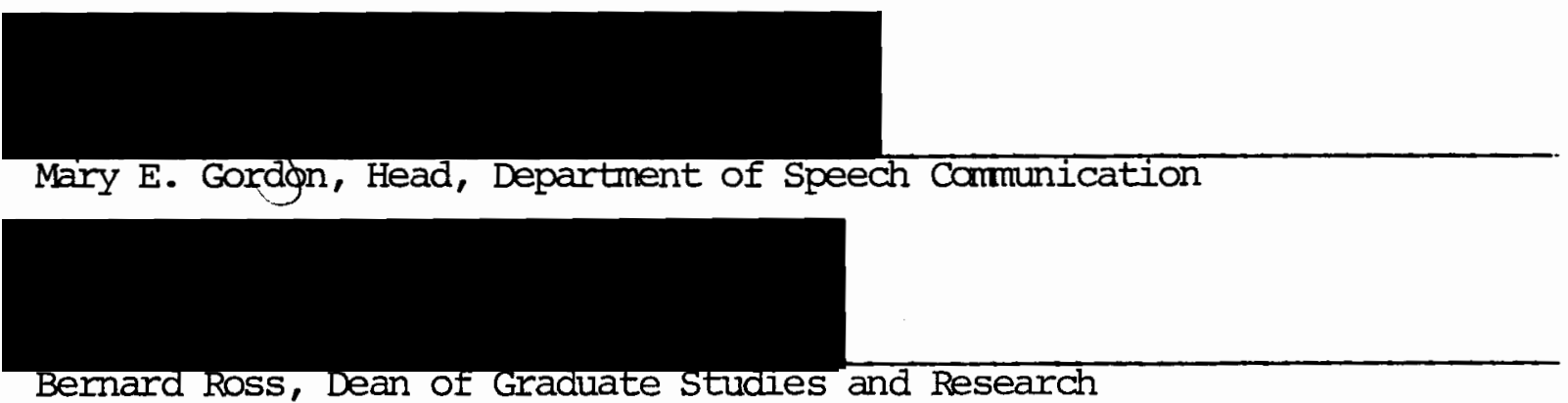

Bernard Ross, Dean of Graduate studies and Research 


\section{ACKNOWLEDGMENTS}

I would like to express my sincere appreciation and gratitude to my camittee members for their valuable assistance. Dr. Milton J. Bennett, Chaiman of the committee, inspired me to do this study and guided me through it with stimulative insights. Mrs. LaRay M. Barna was very supportive of my developing this study from its initial stage and gave me much encouragement. Dr. Stephen A. Kosokoff was also supportive of this study and took time to examine the technology of this paper as well as its content.

I would also like to thank Dr. Clifford Clarke and Dr. Janet Bennett for providing valuable references for completing this study.

I am very grateful for the encouragement of my friends, Kathy and Keith, through whom I have learned a greater appreciation for the importance of intercultural commication.

My special thanks go to Dayna and Kim, who provided the technology necessary for completing this paper.

Finally, I would like to express my deepest love and gratitude to my mother, who has continued to support my endeavor in this country, which is totally foreign to her. 
TABLE OF CONIENTS

PAGE

ACKNOWLEDGMENTS . . . . . . . . . . . . . . . . . . . iii

CHAPTER

INTRODUCTION . . . . . . . . . . . . . . . . I

A. NEED FOR MODIFICATION . . . . . . . . . . . . I

B. PURPOSE OF THESIS . . . . . . . . . . . 3

C. JUSTIFICATION OF STUDY . . . . . . . . . . 4

D. DEFTNITION OF TERMS ............... 6

1. Intercultural Communication

2. Communication

3. Culture

I. WESTERN APPROACH TO INIERCULTURAL COMMUNICATION . • • • • 13

A. INTERCULTURAL COMMUNICATION AS A FIELLD OF STUDY • • 13

B. PROBLEMS IN INTERCULTURAL COMMUNICATION . . . . . 16

1. The Assumption of Similarities

2. Ethnocentrism

3. The Melting Pot

4. Stereotypes and Prejudice

C. IMPROVIING INIERCUITURAI COMMUNICATION . . . . . . 24

1. Recognizing Cultural Differences

2. Cultural Self-awareness

3. Cultural Relativism

4. Pluralism/Multiculturalism/Multicultural Person

5. Communication Skills

a. Empathy

b. Nonjudgmental Attitudes

c. Tolerance for Ambiguity 
PAGE

II. JAPANESE APRROACH TO INTERCULTURAL COMMUNICATION PROBLEMS 36

A. INTERCULTURAL COMMUNICATION AS A FTETL OF STUDY • . 37

B. PROBLEMS IN INTERCULTURAL COMMUNICATION ......41

1. Exclusionary Attitudes

2. Racial Chauvinism

3. The Tendency to Rank Cultures

4. The Lack of Absolute Principles

5. Fonmalism or Imposition of the Japanese Conmunication Patterns

III. CONTRAST AND COMPARISON OF WESTERN AND JAPANESE APPROACHES TO INTERCULTURAL COMMUNICATION PROBLFMS . . . . . . . 58

A. FUNDAMENTAL CULTURAL DIFFERENCES BETWEEN THE WEST AND JAPAN . . . . . . . . . . . . . . . . 58

B. RELEVANCE OF WESTERN APPROACH TO THE JAPANESE CULTURAL CONIEXT . . . . . . . . . . . . . 6 63

1. The Assumption of Similarities

2. Ethnocentrism

3. The Melting Pot

4. Stereotypes and Prejudice

C. INTERCULTURAL COMMUNICATION PROBLEMS PECULIAR TO THE JAPANESE . . . . . . . . . . . . . . 73

IV. JAPANESE APPROACH TO IMPROVING INTERCULTURAL COMMUNICATION:

MODIFICATION OF WESTERN APPROACH . . . . . . . . . . 76

A. STUDY OF INTERCULTURAL COMMUNICATION . . . . . . 77

B. REIEVANCE OF WESTERN APPROACH TO THE JAPANESE

CULTURAL CONIEXT . . . . . . . . . . . . . 83

1. Recognizing Cultural Differences

2. Cultural Self-awareness

3. Cultural Relativism

4. Pluralism/Multiculturalism/Multicultural Person

5. Communication Skills

a. Empathy

b. Nonjudgmental Attitudes

c. Tolerance for Ambiguity

C. JAPANESE APPROACH TO IMPROVING INTERCULTURAL COMMUNICATION . . . . . . . . . . . . . . 94 
V. APPLICATION OF JAPANESE APPROACH TO INTERCULTURAL COMMUNICATION . . . . . . . . . . . . . . 96

A. INTERCULTURAL COMMUNICATION WORKSHOP AT PSU . . . . 97

B. MODIFICATION OF ICW AT PSU FOR JAPANESE CONTEXT . . 102

C. FUUI XEROX INIERRCULTURAL COMMUNICATION SEMINAR . . . 110

D. MODIFICATION OF FUJI XEROX ICC SEMINAR ..... . 113

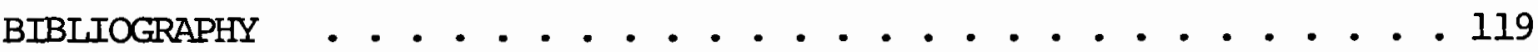




\section{INTRODUCIION}

\section{A. NEED FOR MODIFICATION}

Even a cursory look at the history of Japan reveals a tremendous amount of influence received from foreign countries. As Reischauer (1978) states, "already by the sixth century there had been a heavy flow of cultural influences into Japan fram the nearby continent" (p. 43). Since those early times, massive cultural borrowing has been a conspicuous characteristic of the Japanese attitude toward foreign cultures.

The Japanese, however, have never neglected to maintain their cultural identity in the process of adopting foreign cultures. Nakamura (1964) points out that "they try to recognize the value of each of these different cultural elements, and at the same time they endeavor to preserve the values inherited from their own past" (p. 400). Whenever Japanese adopt foreign elements, they consider it necessary to modify them to blend into Japan's cultural climate. In fact, Japanese are comfortable with only those foreign things which have been "transplanted to Japan and somehow 'Japanized'" (Christopher, 1983, p. 181).

Borrowing from foreign countries is also evident in various fields of social science. When it comes to the adoption of social science, however, the Japanese seem to have paid little attention to the necessity of modification. Kimura (1972) points out that the Western ways of thinking which underlie Western psychology or psychiatry 
have been translated to the Japanese language and accepted without any examination of their appropriateness to the Japanese context. He argues that it is problematic to import those Western disciplines, which deal with human minds, without any adjustment (p. 183). Hamaguchi (1982) maintains that social science, which originated in the west, tends to reflect the fundamental Western value of individualism (p. 15). It seems necessary to adapt and modify theories and concepts of Western social sciences if they are to be used for analyzing Japanese minds and their social behavior.

The field of intercultural communication, which has just been introduced to Japan, is no exception. It has been developed based on Western social sciences, and is likely to be culture-bound. Saral (1979) contends:

The academic study as well as the professional practice of intercultural communication, as it is known today, has to a great extent been conceived and nurtured by scholars and practitioners who are themselves the product of Western thought and training (p. 397).

Cultural biases fram the United States may be especially evident in the field. Stewart (1980) points out:

Most theories, and applications as well, have been tinted by traces of American culture, since the field originated in the United States, and this perhaps interferes with an objective treatment of cultural differences (p. 1).

Too much attention to the individual as a unit of analysis may need rectification:

What is necessary is a shift from the narrow sociopsychological perspectives with their concentration on how the individual is constituted within a culture to the broad patterns found in cultural contexts. Such work will serve as the needed corrective to the founding interculturalists' emphasis on individual attitudes, values, and perceptions by refocusing attention on the broad ideological questions 
that impinge on our communication with persons from other cultures (Asante, 1980, p. 402).

It has been widely acknowledged that there are huge differences between Western culture and Japanese culture in basic assumptions about reality and human nature, values, and beliefs. It is not likely that Western ways to deal with intercultural communication will suit the Japanese context without adjustment. This paper explores the need for modification of Western ideas in the field of intercultural communication for the study of this subject by Japanese.

\section{B. PURPOSE OF THESIS}

The purpose of this thesis is to identify ideas in the field of intercultural communication in the United States which are not relevant or appropriate to the Japanese context, and to modify them in such a way that Japanese could study this subject based on culturally-appropriate assumptions.

Chapter One will describe the condition of the field of intercultural communication in the United States and will present the Western approach to intercultural communication in two parts: descriptions of potential problems in intercultural communication and suggestions which have been proposed for improving intercultural communication. This will be done by a general review of the literature on intercultural comminication in the United States.

Chapter Two will begin with describing the condition of the field of intercultural communication in Japan. It will then introduce a Japanese approach to intercultural commuication. The Japanese tendencies and attitudes which are likely to interfere with successful intercultural 
communication will be identified and described based on literature on the Japanese culture and people. Unlike Chapter one, this chapter will not discuss how the Japanese could improve intercultural communication since there is not enough literature for such discussion fram the Japanese point of view.

Chapter Three will explore differences and similarities in intercultural communication between the Western approach and a Japanese approach. The comparison is offered to provide a foundation for discussing a Japanese approach to improving intercultural communication in Chapter Four. The prescriptions in the Western approach will be examined and modified for Japanese use. Finally, Chapter Five will inquire into training practices for Japanese to improve intercultural conmunication. This paper, thus, compares intercultural carmunication problems of Westerners and Japanese, and based on this comparison, identifies ways for Japanese to improve intercultural communication by modifying Westerners' suggestions for effective intercultural communication. It also discusses application of the above content.

\section{JUSTIFICATION OF STUDY}

There is little literature on intercultural cormunication which is written based on the Japanese assumptions of reality and human nature. It is true that there are many studies on the values or cammunication behavior of the Japanese (Cathcart \& Cathcart, 1982; Morsbach, 1982, etc.), or the contrasts between Japanese and other cultures in these areas (Okabe, 1983). They are, however, mostly based on western ideas of intercultural communication and do not deal with basic questions such as what kinds of problems the Japanese are likely to encounter or 
display in intercultural cormunication, given their cultural assumptions. The characteristics of Japanese problems may be different fram those of Westerners' problems. If this is the case, how could Japanese overcome their problems? It would be necessary to modify western ways to improve intercultural conmmication if they were to be adopted by the Japanese. This paper will address these basic questions, which have been raised, but not explored (Prosser, 1978), or have been discussed on a limited scope (Inamura, 1980) .

It is hoped that this paper will enhance the study of intercultural communication in Japan as it makes the content of the study more appropriate to the Japanese. When, as will be discussed later, the very concept of cammunication is unfamiliar to Japanese, it is unlikely that the theories and ideas of intercultural communication fram the West will be accepted and understood smoothly by them. For the subject of intercultural communication to be studied by Japanese, it should be accomodated to their cultural frame of reference. This paper is aimed at meeting that need.

It is also hoped that this paper will contribute to the area of training. There has been a growing interest in training programs on intercultural cormunication among Japanese, especially in the business context. But the design of programs is usually based on Western thought. Japanese trainees might be able to benefit more from programs which acknowledge their own cultural assumptions. This paper offers some suggestions for designing more suitable training programs for Japanese.

In addition, this paper hopes to promote the understanding of the Japanese among non-Japanese. It could help them to understand Japanese behaviors, attitudes or problems in intercultural communication, and to 
find ways to achieve mutual understanding.

\section{DEFINITION OF TERMS}

The three terms which are central to this paper will be defined. They are "intercultural communication," "communication," and "culture."

\section{Intercultural Communication}

Intercultural communication is broadly defined by Porter and Samovar (1982) as communication that "occurs whenever a message producer is a member of one culture and a message receiver is a member of another" (p. 27). While this definition does not specify the nature of communicators, Hoopes and Pusch (1979) indicate it in their definition:

Intercultural cammunication refers to the commmication process (in its fullest sense) between people of different cultural backgrounds. It may take place among individuals or between social, political or econamic entities in different cultures, such as govermment agencies, businesses, educational institutions or the media (p. 6).

Harms (1973) eliminates, from his definition of intercultural communication, communication that is "engaged in by diplomats and government leaders," or communication through media. He calls such communication cross-cultural communication (p. 40). Prosser (1978) makes a similar distinction:

Intercultural cammunication can be defined simply as that interpersonal communication on the individual level between members of distinctly different cultural groups. Crosscultural communication can be defined simply as the collective communication between cultural spokespersons of different cultural groups or between whole cultural groups (pp. xi-xii).

This distinction will be used in this paper. Intercultural communication will refer to communication between individuals of different cultures. It does not include cormunication between officials of 
nations, or other formal entities, when their purpose is mainly to represent their organizations.

\section{Communication}

It is difficult to define the concept of communication for this paper, which will explore conmmication by the Japanese. For one thing, the nature of communication differs across cultures, and a culture-free definition of cammunication has yet to be given. Saral (1979) contends:

Whereas we readily acknowledge that different cultures perceive and communicate reality differently, we are still finding it difficult to question the very culture-bound assumptions underlying the prevelent theories and models defining the nature and scope of the concept "communication" itself (p. 399).

For another thing, there exist no words in the Japanese language which are equivalent to the English word, "canmunication," except the loarword, "kaminikeishon." It seems inevitable to rely on Westerners' definitions of this term at present. "Communication," as used in this paper, will be defined as it pertains to intercultural communication. It has four components.

First, the term "communication" here will refer to face-to-face communication as opposed to cormunication through mass media. Harms (1973) describes intercultural communication as "participant communication" which is "characterized by intense involvement on the part of the participant communicators" whereas the use of mass media is characteristics of cross-cultural cammunication (p. 41). Howell (1977) concurs with this view:

Ideally, cross-cultural communication is confined to mass media while person-to-person communication is desirably intercultural (p. 4).

In face-to-face communication, the second component of the definition becomes significant. That is, communication will refer to any 
behavior to which meaning is assigned. This view of conmunication has been adopted by many intercultural communication scholars. For example, Porter and Samovar (1982) define communication as "that which happens whenever meaning is attributed to behavior or to the residue of behavior" (p. 28). Likewise, condon and Yousef (1975) state:

- . there was communication if we are referring to any behavior that is perceived and interpreted by another, whether or not it is spoken or intended or even without the person's conscious awareness (p. 2).

Language is not the only means to communication. Communication "has occurred when one person assigns meaning to a verbal or nonverbal act of another" (Sarbaugh, 1979, p. 2).

Third, communication is relational. Harms (1973) describes intercultural communication as two-way where "the participants exchange information and form unique associations or relationships" as opposed to oneway cross-cultural communication (p. 41). In this view, communication "involves mutual impact or influence, with all parties simultaneously influencing all other parties" (Tucker, Weaver \& Berryman-Fink, 1981, p. 274). Rogers and Kincaid (1981) state:

Communication is always a joint occurrence, a mutual process of information-sharing between two or more persons. In other words, communication always implies relationship (p. 63).

That communication is relational is recognized as one of the axioms of cammunication postulated by Watzlawick, Beavin and Jackson (1967, p. 54). Viewing communication as relational, not as the mere exchange of information, is especially important for this paper since the Japanese tend to perceive their identities in their relationships with others, and to emphasize the relational aspect of cammunication.

Finally, communication will be seen here as a process. The concept 
of communication as process has been widely accepted since the publication of The Process of Communication by Berlo in 1960. A process model of communication makes a sharp contrast with linear models in which commmication is seen as unidirectional. Tucker, Weaver and BerrymanFink (1981) state:

A process is a continuous interaction of a large number of factors, with each factor affecting every other factor, all at the same time. A process approach views events and relationships as dynamic, ongoing, ever-changing, and continuous. A process is not a fixed sequence of events having a beginning and end (p. 273).

Looking at communication as a process is essential for the study of intercultural communication. When communication is seen as having fixed linear causality, we cannot transcend our cultural boundaries. For this view leads us to see only a certain set of cause and effect, but not another, or prevents us from perceiving communication from totally different perspectives. Furthermore, the linear view of communication is thought to be a product of Western thought which emphasizes the independence of individual elements while dismissing the importance of the relationship aspect (Saral, 1979, p. 398). It is when we view communication as a process that it will became possible for us to shift our cultural frame of reference to fit to another.

In short, the term "commmication" is defined for this paper as a relational process of face-to-face behavior to which meaning is assigned. When communication is defined this way, the goal of communication cannot be merely the transmission of information. Rogers and Kincaid (1981) state:

Communication is defined as a process in which the participants create and share information with one another in order to reach a mutual understanding (p. 63). 
In this paper, mutual understanding will be considered to be the goal of intercultural commication. People will try to reach this goal when they aim toward improving intercultural communication.

\section{Culture}

The concept of culture has been defined in various ways in different fields of study. Barnett and Kincaid (1983) state:

Definitions of culture center upon extrinsic factors such as the artifacts that are produced by society (clothing, food, technology, etc.), and intrinsic factors such as the beliefs, attitudes, perceptions, and values of a society (p. 171).

In the field of intercultural conmunication, the emphasis has been placed upon "intrinsic factors," or those aspects of culture which have been internalized by members of the culture rather than "extrinsic factors," or material objects and institutionalized systems of a society. Prosser (1978), for example, emphasizes that "culture includes the passing on of language patterns, values, attitudes, beliefs, customs, and thought-patterning" (p. 153). Hoopes and Pusch (1979) define culture as:

.. the sum total of ways of living; including values, beliefs, esthetic standards, linguistic expression, patterns of thinking, behavioral nonms, and styles of communication which a group of people has developed to assure its survival in a particular physical and human environment (p. 3) .

Culture seen in the above manner can be called "subjective culture" since it is "located in human minds and hearts" (Prosser, 1978, pp. 160161). Subjective culture is of prime importance in the field of intercultural communication since it has significant impact on the way people communicate. Brembeck (1977) contends that "we communicate essentially in terms of our culturally derived thoughts and behaviors" (p. 13) .

As the concept of perception has been recognized to be important 
for understanding cultural differences, this concept has become a basis for defining "culture," or "subjective culture." Singer (1982), for example, defines culture as "a pattern of perceptions and behavior which is accepted and expected by an identity group" (p. 56). Triandis (1972) defines "subjective culture" as "a cultural group's characteristic way of perceiving its social environment" (p. 3).

For this paper, the definition offered by Triandis will be used. Culture is defined as aspects of subjective culture, including thought patterns, beliefs, values, and verbal and nonverbal behavior.

When culture is defined based on perceptual systems, a group of any number of people can be called a culture insofar as they share the same perceptual system. Kim (1984) describes different levels of cultural group membership:

The canmon referents of the term, culture, generally include: world regions (such as Eastern culture and Western culture), world subregions (such as North American culture and Southeast Asian culture), national culture (such as French culture and Japanese culture), ethnic-racial groups within a nation (such as Black American culture and Mexican American culture), and various sociological subgroups categorized by sex, social class, geographic regions, and countercultural groups (such as Hippie culture, prison culture, and street culture), among others (p. 17).

In this paper, the focus will be on the cultures of nations or large regions such as Japanese culture and Western culture.

As a prerequisite to the following discussion, the definitions of the three major concepts of the study of intercultural cammunication have been given. Intercultural communication will refer to communication between individuals of different cultures. Communication is defined as a relational process of face-to-face behavior to which meaning is assigned. Culture is defined as aspects of subjective culture, including 
thought patterns, beliefs, values, and verbal and nonverbal behavior, and will refer to either the culture of a nation or the culture of a large region in the world.

In the following chapters, I will investigate the possibility that modifying the Western approach to intercultural communication would make the study of this subject more effective for Japanese learners. I will first describe the Western approach to intercultural communication. Next, I will introduce Japanese intercultural conmunication problems, and compare and contrast them with Western problems. I will then present Japanese ways to improve intercultural camminication by modifying Western strategies for effective intercultural communication. 
CHAPTER I

WESTERN APPROACH TO INTERCULTURAL COMMUNICATION

In this chapter, I will look at intercultural communication from the Western perspective. I will first discuss the condition of the field of intercultural conmunication in the United States, and describe the underlying assumptions of the study of this field. I will then describe the Western approach to intercultural commmication. It will refer to general trends of ideas in this field, which have been developed based on social sciences in Western countries. I will describe this approach in terms of two areas: one focuses on problems in intercultural cormunication as percived by Westerners, the other on Westem ideas on how to improve intercultural communication.

\section{A. INTERCULTURAL COMMUNICATION AS A FIELD OF STUDY}

While the origin of intercultural communication can be traced back to ancient times, when people from different cultures first interacted, the field of intercultural communication is still new. Saral (1977) states that "the field of intercultural communication is relatively young, and its boundaries are not yet clearly identified" (p. 389). Asante, Newmark and Blake (1979) concur with this view:

It is still not possible to set firm boundaries for the field of intercultural commuication, which borrows from many disciplines, but it can be assumed to cover the relationship of culture to human interaction (p. 14).

Many scholars have recognized this field as related to the discipline of 
speech cormunication. Burk (1975), for example, states that "intercultural communication is a sub-field of speech communication that focuses upon the communication transactions across cultural boundaries" (p. 35). Kim (1984) considers intercultural communication to be "one of the newer subsystems of cammunication" (p. 14).

The field of intercultural commmication incorporates the studies of culture and communication. Porter and Samovar (1982) describe the birth of this field as "the marriage of culture and communication," and say:

Inherent in this fusion is the idea that intercultural communication entails the investigation of culture and the difficulties of commicating across cultural boundaries (p. 27).

Brembeck (1977) states that the study of intercultural communication includes "a review of the basic nature of culture, or communication, and of their relationships" (p. 13).

communication as an important discipline is widely recognized in the Western world. Prosser (1978) states that "today in Western societies, especially in the United States, the study of communication, and specifically the study of interpersonal, oral, and mass communication, has become a very important endeavor" (p. 14). Underlying this recognition of communication as a discipline is the assumption that communication can be improved through systematic study. Harper (1979) found that one of the main elements for the definition of communication throughout the history of this field was "a natural ability that can be improved by study" (p. 262).

The concept of culture has been studied in various fields such as anthropology, sociology and linguistics. In the field of intercultural communication, aspects of subjective culture are of prime importance. 
It has been claimed and demonstrated that such aspects of culture as values, beliefs, and verbal and nonverbal behavior can be scientifically studied. Triandis (1972), for example, explores methods of analyzing various elements of "subjective culture" such as values, attitudes, nonms and roles. In the area of values, Kluckhohn and Strodtbeck (1961) presented a theory and the research instrument for the cross-cultural testing of the theory. Cross-cultural differences in nonverbal behavior have been systematically investigated by many authors in the field such as Jensen (1982) and Morsbach (1982).

It is clear that, in the Western world, both communication and culture are treated as subjects that can be studied. As Prosser (1978) points out, "the need to define and study communication and culture explicitly is essentially Western, and even more essentially characteristic of the United States" (p. 12). It is assumed that intercultural communication can be studied on the basis of the systematic research and study of those two areas:

Intercultural communication research should describe the interdependence of communication and culture. Careful observation and astute analysis of communication and culture promise to assist researchers in understanding the interaction of these complex systems and the broad relationships of other variables (Burk, 1975, p. 36).

Although the field is still new, an increasing number of people have recognized the importance of the study of intercultural communication. The growing interest is seen in the dramatic increase in published books and articles, in the increasing number of conferences, and in the increase in intercultural communication courses offered at universities and colleges.

The growth of the field has been built upon the recognition that 
intercultural communication is difficult. People have come to realize that "intercultural contact not only is inevitable but often is unsuccessful" (Porter \& Samovar, 1982, p. 27). There have been "needs in meeting practical intercultural 'problems'" (Kim, 1984, p. 13). Hoopes (1979) points out that the field "emerged from immediate experience and was built upon practical need" (p. 10). The field has been established to meet the need to overcome intercultural problems. Burk (1976) maintains:

Intercultural communication is intended to develop channels for understanding, avoiding pitfalls leading to conflicts, and resolving conflicts that arise in transactions across cultures (p. 26).

The study of intercultural communication is to "identify the 'barriers' to communication across cultures," and to "perfect the communication process" (Asante, Newmark \& Blake, 1979, p. 20). In the following sections, the Western approach will be discussed in these two areas.

\section{B. PROBLEMS IN INTERCULTURAL COMMUNICATION}

The central issue of the field of intercultural conmunication has been considered to be that of differences between cultures. Stewart (1978), for example, states that "it is on this issue of differences, either naturally or by aoquisition, that intercultural communication rests its claim for identity" (p. 272). Asante (1980) also maintains:

Cultural differences, not cultural similarity, is the premise of the field of intercultural communication. . . . The field grew as an effort to capture the essential elements of difference between people of diverse cultural backgrounds (p. 401).

In the Western approach, difficulty in intercultural communication is associated with various kinds of differences between cultures. Hoopes 
(1979) maintains that "in basic communication theory, differences are seen as barriers while similarities provide the matrix in which communication is made possible" (p. 33). Likewise, Prosser (1978) states:

Many studies have illustrated that the more the people have in cormon with each other, the less likely they are to suffer serious breakdowns in communication and cultural distortion (p. 6).

In the following section, I will discuss the Western approach to intercultural cammication problems. I will describe four categories of problems which have been. identified by many authors in the field. These are: the assumption of similarities, ethnocentrism, the melting pot, and stereotypes and prejudice.

1. The Assumption of Similarities

Assuming similarities in the face of cultural differences is indicated as a source of problems in intercultural communication. Barna (1982) argues taht "the hazard of assuming similarity instead of difference" is a stumbling block to intercultural communication (p. 326). Szalay (1974) cautions against assuming similarities in intercultural contact:

In intercultural communication we cannot automatically assume that our partner or audience has the same concepts, beliefs and values as we do. If we work under such assumptions, we are bound to make numerous mistakes and will have little chance to relate meaningfully to our partner (p. 2).

People assume similarities in various areas. One of these areas is nonverbal behaviors. Condon and Yousef (1975) maintain that "there is a common notion that most of the topics included in the nonverbal area are universal, natural, and not learned" (p. 125). Since nonverbal behavior is largely outside of our awareness and we use it spontaneously, we tend to assume it is universally-shared, natural human behavior. 
Patterns of thought are another area of assumed similarities. Porter and Samovar (1982) point out that "unless they have had experiences with people from other cultures who follow different pattems of thought, most people assume everyone thinks in much the same way" (p. 40). Stewart (1978) also contends that "most communicators assume a universal pattern and do not have an insight into the various patterns in cultures" (p. 311). While we are usually aware of differences in vocabulary and grammar between different languages, we tend to overlook the differences in the ways we use those languages to express ourselves.

Whereas people are generally able to recognize cultural differences in some areas, they seem persistent in seeking fundamental similarity. Bennett (1979) argues:

. . , while most people acknowledge superficial behavioral differences in dress, custom, language, etc., it takes but a scratch of this surface to encounter a basic belief in the essential similarity of all people. . . . Attempts to point out more fundamental value differences may even be met by hostility-an indication of how central the assumption of similarity is to our world view (pp. 407-408).

People may assume similarities without being aware of doing so.

Barna (1982) states:

Each of us seems to be so unconsciously influenced by our own cultural upbringings that we at first assume that the needs, desires, and basic assumptions of others are the same as our own (p. 323).

Hoopes (1979) makes a similar point:

We also make assumptions about the way other people think based on shared values and experiences, what the psychologists call "projected cognitive similarity." This is the basic unconscious belief that other people think and view the world the way we do (p. 34).

The people who hold the assumption of similarity are likely to refuse to see differences which actually exist in the communication context: 
The assumption of similarity is not just a passive perspective-it also defines what will be actively sought. Thus, the observer notes and imputes importance to human similarities while ignoring or downgrading the importance of human differences (Bennett, 1979, p. 408).

Harris and Moran (1982) also discuss our tendency to ignore differences:

We are affected by the cormon lore of the cormunity in which we are raised and reside, regardless of the objective validity of this input and imprint. We tend to ignore or block out that which is contrary to the cultural "truth" or conflicts with our beliefs (p. 63).

People with this assumption may judge cultural differences negatively. Barna (1982) maintains that "it is very easy to dismiss strange or different behaviors as 'wrong', listen through a thick screen of value judgments, and therefore fail miserably to achieve a fair understanding" (p. 328). Brislin (1981) argues that people "become intolerant of people both from within and outside the culture who deviate in some way" (p. 5) .

This assumption of similarities impedes intercultural communication because it prevents us from reoognizing and understanding cultural differences. It leads us to treat people from other cultures in the same way we treat ourselves, regardless of their needs or desires, which may be totally different from our own. It blinds us to actual cultural differences and makes us react negatively toward them.

\section{Ethnocentrism}

The tendency to see other people from our own perspective is said to be problematic in intercultural communication. Harris and Moran (1982), for example, state:

We each tend to view other people's behavior in the context of our own background, that is, we look at others from the perspective of our own "little world" and are thus subjective (p. 63). 
We tend not only to view others from our own frame of reference, but to believe that our way is the right way. In his discussion of difficulties in cross-cultural interaction, Brislin (1981) writes:

The product of a culture's influence, then, is a resicue of behaviors, ideas, and beliefs with which people are comfortable and which they consider "proper" or "the right way" (p. 6).

These tendencies may be called ethnocentrism. It is acknowledged that Sumer (1906) introduced this concept. He defines it as follows:

Ethnocentrism is the technical name for this view of things in which one's own group is the center of everything, and all others are scaled and rated with reference to it. . . . Each group nourishes its own pride and vanity, boasts itself superior, exalts its own divinities, and looks with contempt on outsiders. Each group thinks its own folkways the only right ones, and if it observes that other groups have other folkways, these excite its scorn. Opprobrious epithets are derived from these differences (p. 13).

As in the case of the assumption of similarities, ethnocentrism appears to be an unconscious tendency (Ruhly, 1976, p. 22).

Ethnocentrism is claimed as a major source of problems in intercultural communication. Hoopes (1979) places this idea at the starting point of the continuum of intercultural learning. Ruhly (1976) views ethnocentrism as "a major cause of misunderstanding in commuication" (p. 22). Samovar, Porter and Jain (1981) discuss this concept as a potential problem in intercultural communication:

If we allow ethnocentrism to interfere with our perceptions, with our interactions and with our interactions, we will reduce the effectiveness of our efforts ( $p$. 195).

Ethnocentrism leads to misunderstanding. As Ruhly (1976) points out, "when we behave ethnocentrically, we do not allow for the possibility of differences in meaning" (p. 22). Interaction between people from different cultures potentially involves various kinds of differences. 
Brislin (1981) states that "often, the same behavior is considered desirable to people from one culture and distasteful to people from the other" (p. 6) . Using one's own cultural frame of reference for interpreting the behavior of others may thus be disruptive in intercultural settings.

Ethnocentrism also leads us to react negatively toward many different ways in which people in the world operate. Burk (1976) writes that "to the well acculturated ingroup member there are two ways to do things, his way, and the wrong way" (p. 23). Hoopes (1979) also discusses this point:

The principle characteristic of the ethnocentric is the relatively blatant assertion of personal and cultural superiority ("my way is the right way") accompanied by a denigration of other cultures and other ways. The ethnocentric impulse is to divide the world into two parts - us and them (the "we-they" conflict) (p. 18).

When people believe that their way is the right way and superior to any other way, they may resist interacting with those who do things differently from their way, or may negatively criticize the strange ways other people behave.

In these ways, ethnocentrism creates problems in intercultural communication. When people are ethnocentric, they will not recognize or deal with cultural differences. Rather, they will dismiss the importance of understanding those differences, and will negatively evaluate them in conmunication.

\section{The Melting Pot}

The assumption of similarities and ethnocentrism may result in the imposition of one's cultural ways on people of other cultures. Folb (1982) maintains: 
Perhaps nowhere is a dominant culture's (those who dominate culture) ethnocentrism more apparent than in the missionarylike work carried on by its members-whether it be to "civilize" the natives (that is, to impose the conquerers' cultural baggage on them), to "educate them in the ways of the white man," or to "Americanize" them (p. 140).

This "Americanization" is referred to as the melting pot. Brislin (1981) describes this concept:

The "melting pot ideal" was that, if immigrants blended into the United States by leaming its language and becoming involved in its institutions, they would have the opportunity to pursue a decent living (p. 27).

This view is likely to create disruptive effects in communication between people of the mainstream culture and immigrants, especially when immigrants do not want to assimilate into the mainstream culture. People from the mainstream culture who hold this idea are likely to impose their own ways without any sensitivity to or respect for the cultural heritage that immigrants have brought to that culture. A basic tenant of intercultural communication is that as long as the melting pot concept prevails in a society, it will be difficult to bring about mutual understanding among different groups in that society.

Today, the term "the melting pot" is seldam heard, but the idea remains in the minds of many people. Bennett (1979) states:

We hear today widespread disavowal of the melting pot in favor of some form of "cultural pluralism." A good part of this disavowal, when it comes from mainstreamers, may be insubstantially rhetorical (p. 410).

The idea of the melting pot prevents people from mutual respect in intercultural communication. It is more problematic when people are not aware of having such a thought themselves.

In this section, the melting pot is treated as one category of problems though it appears to be a result of the assumption of similarities 
and ethnocentrism, discussed in the section prior to this. For the melting pot has been a special issue by itself in this country, and seems to deserve as much attention as the other two issues.

4. Stereotypes and Prejudice

Stereotypes and prejudice are another source of problems in intercultural communication. Stereotypes are "overgeneralized, oversimplified, or exaggerated beliefs associated with a category or group of people" (Samovar, Porter \& Jain, 1981, pp. 121-122). We are inclined to view people fram other cultures on the basis of our stereotypes of those cultures. Although they serve the "human function of ordering the unknown" (Ruhly, 1976, p. 23), they create problems in communication. Barna (1982) contends:

Stereotypes are stumbling blocks for communicators because they inerfere with objective viewing of stimuli--the sensitive search for cues to guide the imagination toward the other person's reality (p. 327).

Ruhly (1976) explains the problems of stereotypes as follows:

Stereotypes, ... . can cause problems in communication when they completely blind us to individual qualities or variations. On the basis of our stereotyped expectations, we may send totally inappropriate messages, messages that confuse or alienate the receiver (p. 23).

Prejudice is "a rigid attitude toward a group, based upon erroneous beliefs or preconceptions" (Samovar, Porter \& Jain, 1981, p. 123). Ruhly (1976) points out that it is "often based on stereotyped beliefs." It is problematic in communication since "the prejudiced person may expect certain messages and behaviors (cues) from the other." Prejudice usually indicates negative attitudes, but Ruhly suggests that it can be positive since "stereotypes may include a link between a group and a positive quality." She points out that positive prejudice also causes problems 
in communication (p. 24).

Samovar, Porter and Jain (1981) explain the problems of stereotypes and prejudice as follows:

If we have strong negative stereotypes and prejudice, we may choose to live and work in settings that minimize the chances of contact with persons from disliked groups. . . . The selectivity in our perception and interpretation produced by stereotypes and prejudice induces distortion and defensive behaviors. . . , if the stereotypes and prejudice are very intense the prejudiced person might engage in active antilocution and discrimination against the disliked group, which can easily lead to confrontation and open conflicts (pp. 126-127).

Thus stereotypes and prejudice are barriers to intercultural communication.

\section{IMPROVING INTERCULIURAL COMMUNICATION}

Because problems in intercultural comminication arise out of cultural differences, the discussion of improving intercultural communication focuses on understanding and dealing with those differences. Same scholars, however, seem to emphasize the seeking of similarity for effective intercultural communication. Samovar (1979), for example, states:

-. . students of intercultural cormunication should appreciate the commonalities found among individuals and cultures. Again, I believe that in the past we have had a fixation on cultural differences to the point of almost excluding investigations into cultural similarities. . . For when intercultural cormunication is successful, be it at the international or personal level, it is because our similarities, not our differences, have linked us together (p. 250).

on the other hand, Hoopes (1979) cautions against an emphasis on cultural similarities:

Differences are central and dealing with them is a fundamental cross-cultural skill. The argument that "we should emphasize our similarities rather than our differences" simply 
perpetuates cross-cultural conmunication difficulties (p. 33).

In this section, I will discuss the Western approach to improving intercultural communication. I will look at the ideas and skills which mainstream scholars in the field, who emphasize the treatment of differences, identify as useful for effective intercultural communication. As I indicated in the introduction to this paper, the goal of effective intercultural cammunication is mutual understanding. The following section addresses the understanding of cultural differences, cultural self-awareness, cultural relativism, and multiculturalism. It also discusses three communication skills: empathy, non-judgmental attitudes, and tolerance for ambiguity.

1. Recognizing Cultural Differences

For effective intercultural communication, we need to realize cultural differences. Bennett (1979) emphasizes the importance of the assumption of differences in interracial and intercultural communication. Saral (1979) states:

In order for us to understand the nature and process of intercultural communication, we must first understand the nature and process of communication as it occurs in different cultures. Specifically, we must learn how different cultures define and experience reality, how their different systems of basic beliefs and fundamental orientations create different contexts within which perceptions, knowledge, and emotions are exchanged and shared (p. 400).

The significance of cultural differences is discussed in many areas, including values, nonverbal behaviors and thought patterns. Among those areas, the topic of perception seens to receive special attention for explaining fundamental cultural differences. Hoopes (1979) describes "perceptual difference" as:

. . the idea that everyone perceives the world differently 
and that members of one culture group share basic sets of perceptions which differ from the sets of perceptions shared by members of other culture groups (p. 13).

Singer (1982) emphasizes perceptions for understanding cultural differences.

We need not only to assume differences between cultures but also to accept and appreciate them for improving camunication. In his discussion on personality traits for successful cross-cultural contact, Brislin (1981) mentions "respect for others with different points of view" (p. 59). When people respect opinions or values which are different from their own, they can understand people from other cultures more effectively. Harris and Moran (1982) discuss a similar point in regard to an international manager:

The cosmopolitan manager, sensitive to cultural differences, appreciates a people's distinctiveness, and seeks to make allowances for such factors when communicating with representatives of that cultural group. One avoids trying to impose one's own cultural attitudes and approaches upon these "foreigners." Thus, by respecting the cultural differences of others, we will not be labeled as "ethnocentric" (p. 71).

2. Cultural Self-Awareness

Many problems in intercultural communication are associated with cultural influences of which we are usually not aware. In the previous section, it was pointed out that assumptions of similarity and ethnocentrism may both be unconscious tendencies. We need to realize how our thought and behavior are culturally conditioned and to become aware of the effect of our culture upon us. Many authors in intercultural communication call attention to the impact of culture on ways of thinking and action. For example, Barnlund (1982) states:

Cultural nonms so completely surround people, so permeate thought and action, that few ever recognize the assumptions on which their lives and their sanity rest. . . Human 
beings, . . . , occupy a symbolic universe governed by codes that are unconsciously acquired and autamatically employed. So much so that they rarely notice that the ways they interpret and talk about events are distinctively different from the ways people conduct their affairs in other cultures (pp. 13-14) .

Developing cultural self-awareness is considered very important for improving intercultural communication. Szalay (1974) maintains that intercultural communication requires cultural self-awareness (p. 2). Hoopes (1979) explains the importance of this cultural self-awareness:

As long as our way of perceiving the world--on which our communication styles and behavior patterns are based--is "out of awareness," it is not accessible to being deliberately changed, managed, understood or influenced. It will continue to contribute to misunderstanding and conflict. This condition alters only as the individual becomes more aware and has more knowledge of the degree to which his perceptions and his behaviors are culturally conditioned--that is, as he develops "cultural self-awareness" (p. 16).

This ability assists in resolving the difficulty of intercultural communication. Harris and Moran (1982) contend that "increasing one's general cultural awareness" is the first stép to "manage cultural differences more effectively" (p. 72). Samovar, Porter and Jain (1981) describe benefits gained fram increased cultural self-awareness:

The problem of unwarranted, culturally conditioned assumptions of projected congnitive similarity can be considerably resolved if we become aware of our own cultural conditioning and if we recognize that our cultural patterns may have influenced our behavior. In other words, cultural self-awareness should make it easier for us to diagnose difficulties in intercultural communication. . . . As we increase our cultural self-awareness we should be able to suspend judgment when confronted in an intercultural encounter by behavior that appears odd (p. 61-62).

Adler (1972) differentiates "cultural awareness" and "self-awareness," although he considers them to be directly related. Similarly, Hall (1977) maintains: 
Self-awareness and cultural awareness are inseparable, which means that transcending unconscious culture cannot be accomplished without some degree of self-awareness. Used properly, intercultural experiences can be a tremendous eye opener, providing a view of one's self seldom seen under normal conditions at hame (p. 212).

Self-awareness, or knowing oneself, is regarded as basic to intercultural communication. Samovar, Porter and Jain (1981) state that "perhaps the first thing we can do to improve our intercultural communication and resolve many of our problems is to know ourselves" (p. 202). Newmark and Asante (1975) also contend:

It is our belief that effective intercultural communication hinges on the ability to understand and know the dimensions of one's identity and to be aware of the structures and elements that comprise "who one is" (p. 55).

In addition, knowing ourselves is an important step in exercising empathy (Bennett, 1979), which is one of the most vital skills in intercultural communication.

\section{Cultural Relativism}

For improving intercultural communication we need to avoid the belief that our way is the only right way. We should realize that other cultures are just as valid as our own. This shift fram absolute to relativistic thinking needs to be emphasized for effective intercultural communication. Harris and Moran (1982) maintain:

. . . it (cultural understanding) should teach us that culture and behavior are relative, and that we should be more tentative, and less absolute, in our human interactions (p. 72).

Brislin, Landis and Brandt (1983) anticipate such a shift in "intercultural behavior":

... , we should expect a move toward a relativism in . . . perceptions and away from seeing the world in terms of moral and behavioral absolutes. Thus, appropriate and necessary behaviors would become more situationally (culturally) specific 
so that the individual could accept a greater variety

of such behaviors both in others and in himself (p. 6).

Saral (1979) also contends that "there is no absolute reality, nor is

there a universally valid way of perceiving, cognizing, or thinking" (p. 81).

No one culture is inherently better or worse than others. This view is often called cultural relativism. Acconding to Hoopes and Pusch (1979) :

Cultural Relativism suggests that cultures cannot be judged or evaluated from a single or absolute ethical or moral perspective. Evaluations are relative to the background from which they arise. No culture's values, ethics or morals as a whole may be judged as inherently superior or inferior to another's (p. 4).

Szalay (1974) considers cultural relativism to be a principle of intercultural communication.

This notion of cultural relativism is very important for overcoming ethnocentrism. As long as people believe in the superiority of their own culture, and evaluate other cultures on the basis of their cultural perspective, they cannot deal effectively with cultural differences. We need to appreciate other cultures as much as our own in order to bridge cultural differences. The idea of cultural relativism needs to be understood before pluralism or multiculturalism can be accepted in a society. 4. Pluralism/Multiculturalism/Multicultural Person

The melting pot conœept should be overcame in order to understand and learn fram the diversity of cultures. As more and more people have become aware of the importance of cultural differences, the idea of cultural pluralism has gained popularity. Hoopes and Pusch (1979) state:

For most thoughtful people, cultural pluralism has replaced the "melting pot" in describing the multiethnic and multicultural 
character of American society. Ideally, members of a pluralistic society recognize the contributions of each group to the common civilization and encourage the maintenance and development of different life styles, languages and convictions ( $p .6$ ).

In a pluralistic society, cultural differences will be tolerated. Brislin (198I) maintains:

- . pluralistic societies encourage or at least tolerate heterogeneity with respect to the values and customs of different groups. - . , members of a pluralistic society see worth in variation. Different sets of religious beliefs are tolerated, skin color is not a criterion of mobility, many different ideas can be freely expressed, and a wide range of behaviors are seen as appropriate in meeting everyday needs of food, shelter, clothing, and interpersonal relations (pp. 288-289).

In pluralistic societies, therefore, more effective intercultural canmunication can be expected as people learn and improve their communication skills for bridging differences.

Pluralism encourages people to become bicultural or multicultural. According to Hoopes (1979), "the fully bicultural person develops a dual cultural personality" (p. 20). Such a person is able to shift fram one cultural frame of reference to the other as the situation changes, and to communicate successfully with people from either culture. A person will be called multicultural if he or she incorporates more than two cultural perspectives. Lum (1982) states that "multicultural persons and culturally pluralistic persons are considered to be people whose actions and thoughts reflect more than one culture" (p. 384). Adler (1982) describes a multicultural man as:

- - a person whose essential identity is inclusive of life patterns different from his own and who has psychologically and socially come to grips with a multiplicity of realities. - . Multicultural man is the person who is intellectually and emotionally committed to the fundamental untiy of all human beings while at the same time he recognizes, legitimizes, 
accepts, and appreciates the fundamental differences that lie between people of different cultures (p. 390).

Although being multicultural may create stress and tension, the notion of multiculturalism helps us understand how to deal with the cultural diversity in the world. This idea not only encourages the acceptance and appreciation of cultural differences, but emphasizes the importance of shifting a frame of reference for successful intercultural communication.

\section{Communication Skills}

For improving intercultural communication, learning the special communication skills necessary for interacting with people from other cultures is just as important as understanding the basic concepts of effective communication. Various communication skills and strategies have been identified as useful for success in intercultural communication. I will discuss three of those skills which are considered important by many scholars in the field: empathy, non-judgmental attitudes, and tolerance for ambiguity.

a. Empathy. Brislin, Landis and Brandt (1983) contend that "the most functional intercultural skill is the ability to take another's point of view" (p. 5). Misunderstanding or perceptual distortion occurs when we perceive others exclusively from our point of view. For effective intercultural communication, we need to overcome our ethnocentric bias and become sensitive to the point of view of other people. Szalay (1974) discusses this need:

. - we must learn to relate to our partner in terms of his frame of reference. To be effective, cormunication has to be adapted to the cultural background and experiences of our partner or audience. This adaptation is a fundamental requirement that lies at the very core of the intercultural 
cormunication process (p. 2).

This skill is often called empathy. Ruhly (1976) states that "empathy is the ability to see the world from another person's point of view," and emphasizes it as one of the two important qualities for successful intercultural communication (p. 29). Samovar, Porter and Jain (1981) also point out the importance of developing empathy. Asante (1980) states that "communication across cultures can only be effective if the communicators have empathy for each other's cultural perceptions" (pp.406-407). Ruben (1982) includes empathy in the seven dimensions of importance to intercultural competence.

For bridging cultural differences, empathy is considered to be indispensable and should be clearly differentiated from sympathy, which may produce problems in intercultural cammunication. Bennett (1972) defines sympathy as "the imaginative placing of ourselves in another person's position," and empahty as "the imaginative intellectual and emotional participation in another person's experience." Bennett (1979) maintains that "the commication strategy most appropriate to multiplereality and the assumption of difference is empathy" (p. 417). Stewart (1978) identifies two kinds of communication interfaces: sympathy and empathy. He states:

Under conditions of cultural difference, empathy is the better interface. It does not assume similarities among cormunicators to the degree of sympathy (p. 313).

While sympathy may be effective in certain contexts, it is empathy which is really helpful for understanding people from other cultures.

b. Nonjudgmental Attitudes. Our tendency to judge other people based on our frame of reference or to evaluate their different behavior negatively was discussed earlier as a problem in intercultural communication. 
We need, then, to withhold our judgmental attitude in order to improve communication. Hoopes (1979) considers "resisting judgmental reactions" to be helpful for bridging cultural differences (p. 35) . After a review of the research on cross-cultural effectiveness, Ruben (1982) regards "the capacity to be nonjudgmental" (p. 333) as one of the most important skills. Ruhly (1976) discusses "the ability to perceive and consider alternative explanations" (p. 28) as an important quality, which seems to imply the value of being nonjudgmental. Barna (1982) also maintains that people need "to develop an investigative, nonjudgmental attitude" for successful intercultural communication.

c. Tolerance for Ambiguity. Related to the nonjudgmental attitude is tolerance for ambiguity. In intercultural communication, we need to tolerate unfamiliar and ambiguous situations without judging them hastily. Brislin (1981) considers tolerance for ambiguity to be an important skill in cross-cultural contact. According to him, "tolerance for ambiguity means an ability to think about problems and issues even though all facts and probable effects of decisions are not known" (p. 55). Such an ability is necessary when one must communicate with people whose values and beliefs are unknown, and must act on the basis of tentative assumptions which require constant modification. Ruben (1982) states that "the ability to react to new and ambiguous situations with little visible discomfort can be an important asset when adapting to a new environment" (p. 335) .

In summary, this chapter has discussed the condition of the field of intercultural communication in the United States and the Western approach to intercultural communication. The field is considered to be 
important by Westerners, who have recognized difficulty in this area. It is assumed that intercultural communication can be studied and improved through scientific and systematic research on the natures of culture and communication, and their relationship.

The Western approach to intercultural cormunication has been discussed in two areas: intercultural communication problems and ideas for improving intercultural cormunication. Four categories of problems, which have appeared repeatedly in the literature of the field, have been described. The "assumption of similarities" is a barrier to intercultural communication where differences, rather than similarities, play a major role. "Ethnocentrism" is regarded as the main source of problems in intercultural communication. Ethnocentric people boast of their cultural communication. Ethnocentric people boast of their cultural superiority, interpret and judge others from their own standards, and negatively evaluate cultural differences. The "melting pot" appears to be a result of the above two problems. The belief that other people want, or should want, to became like one's cultural group leads to the imposition of one's own ways on them. Finally, "stereotypes and prejudice" were discussed. Preconceived ideas and evaluation of a group of people will distort communication with them.

The Western approach to improving intercultural communication was presented in terms of four ideas and three communication skills. "Recognizing cultural differences" is essential for effective communication. "Cultural self-awareness" is also indispensable. It says that we need to realize the influence of culture upon us. The notion of "cultural relativism" fosters nonevaluative attitudes and respect for other cultures. The ideas of "pluralism, multiculturalism, and the mutlicultural 
person" encourage us to accept and adapt to more than two cultures and to have, as a goal, the ability to shift between them. "Empathy," the ability to take another's point of view, is considered the most important skills for improving intercultural communication. "Nonjudgmental attitudes" and "tolerance for ambiguity" are also essential. The authors surveyed imply the following prescriptions: we have to stay away from judging people of other cultures from our own cultural perspective; and we need to tolerate the ambiguity manifested in the intercultural setting without hasty evaluation. 
CHAPTER II

JAPANESE APPROACH TO INTERCULTURAL COMMUNICATION PROBLEMS

In this chapter, I will look at intercultural communication from the Japanese perspective. I will first describe the condition of the field of intercultural cormunication in Japan as it seems important to discuss the Japanese perception of the field for the subsequent development of this paper. Then, I will present a Japanese approach to intercultural cammunication problems, which will address general tendencies and attitudes of the Japanese which are likely to interfere with effective intercultural cammunication. There is not much literature on intercultural communication based on Japanese assumptions of reality and human nature. Therefore, I will identify potential intercultural problems of the Japanese by borrowing ideas and notions fram the literature on Japanese culture and people. That literature provides enough examples of Japanese intercultural problems, although they do not directly refer to ideas in the Western approach. However, it seems difficult to discuss how the Japanese can improve intercultural communication without referring to the Western approach. So, I will discuss a Japanese approach to improving intercultural communication in Chapter Four by using and modifying Westem ideas and suggestions for effective intercultural cormunication. 
A. INTERCULTURAL COMMUNICATION AS A FIELD OF STUDY

The concept, needless to say the field, of intercultural commuication did not exist in Japan until the idea was recently introduced from Western countries. Even though the concept has been accepted since then, the number of universities which offer courses in intercultural communication is still very limited. And intercultural communication is not usually taught as an independent discipline. Stewart (1980) supports this observation:

... intercultural communication is nearly inseperable from teaching English. The intimate link supports English instruction, but blocks developing the potential of intercultural communication in the areas of cultural analysis. The adhesion to English, and languages generally, also discourages developments of intercultural communication in the fields of political, diplamatic and business negotiations (pp. 15-16) .

Being part of English instruction, the study of intercultural communication in Japan deals only with communication between English-speaking people and Japanese, ignoring other kinds of intercultural communication such as communication with Asians or Africans.

The two major concepts in the field of intercultural communication, culture and communication, also did not exist until recently in Japan. Prosser (1978) states:

... , the modern Japanese have not even had terms, until recently, for such ideas as communication apart from language, or culture apart from nation, or intercultural communication (p. 14).

The Japanese version of the English term "cormunication" is part of a group of Japanese words called gairaigo, which have been introduced to Japan from other countries and have became part of the Japanese vocabulary without being translated to Japanese words. When a new concept is 
introduced to Japan from outside, a Japanese word which refers to or resembles the concept will usually be sought. When there is no appropriate Japanese word, a new word will be invented, or the foreign word will be kept and romanized to suit Japanese pronunciation and will eventually become gairaigo. The word "kaminikeishon" is a gairaigo, which has never been translated to Japanese.

Nakano (1982) points out that the Japanese did not have the term or concept which referred to the totality of various communication activities prior to the arrival of the English word "communication." He explains that the reason why "communication" has become gairaigo is that the English concept of communication does not fit the nature of Japanese conduct of speaking and listening (p. 146).

Hamaguchi (1977) presents a somewhat different reason for the absence of the concept of communication in Japan. He argues that when individuals in a society are independent agents of action, as in Western societies, communication is necessary as an intermediary means for them to relate to one another for the maintenance of their society. But he points out that social interaction itself cannot be an artificial intermediary means for the existence of the Eastern self. Japanese or Eastern people rarely perceive human existence as centered in each individual. Rather, the existence of the Eastern self resides between people. Its existence is perceived as encompassing his or her relationship with others. In a social structure in which people are interdependent, social interaction itself is an indispensable, intrinsic, and primary factor, and is a natural phenomenon. Hamaguchi contends that the concept of conmunication is not necessary to the Japanese who perceive various interpersonal and psychological processes as intrinsic factors in the 
structure of human existence (pp. 121-125).

Kimura (1972) elaborates on how the Japanese perceive their existence. He argues that a certain something must exist before the Japanese self comes into existence. He calls this "something" the space between people. "Space between people" is a prerequisite to the existence of the Japanese self. Self will come into existence the moment it encounters what is not self. But it is not that self brings what is not self into existence, or that what is not self calls self into existence. Self and what is not self come into existence simultaneously from the space between them at the moment they meet each other (pp. 14-15).

In the introduction of this paper, communication is defined as relational and as a process. This Western conceptualization of communication assumes at least two entities. Before communication takes place, there exist at least two independent, separate selves. These selves will became interrelated as communication goes on. On the other hand, the Japanese self needs a relationship with another self in order to come into existence. To put it another way, it exists in the state of connection. Interconnectedness or relationship, which is assumed to be developed through conmunication in the Western definition, is a presupposition to the existence of the Japanese self. It can be said that the process of communication is built into the structure of human existence. It is difficult for Japanese to objectify or conceptualize communication which is the very foundation of their existence. Thus, the Japanese fundamental assumptions regarding human existence defy the development of the concept of communication.

Since the Japanese have trouble conceptualizing "communication," it seems impossible for them to think that it can be studied systematically. 
Stewart (1980) argues:

. . , there exists in Japan a deep underlying resistance to a technical or professional treatment of speech-communication. . . . it delays the development of curricular courses of study in the field of speech-communication, generally delivering a setback to the development of the science and art of commuication (p. 15).

In contrast to the study of communication, the study of Japanese culture has attracted many people in Japan. Scholars fram the fields of sociology, psychology and the like have discussed various aspects of Japanese culture and people. There are also many Westemers who have written about Japanese culture. The study of Japan and the Japanese has become so popular, even among conmon people in Japan, that a new term has been created for the field; Nihon-ron or Nihonjin-ron, meaning roughly the Japan-debate or the Japanese-debate. Reischauer (1978) states:

A spate of books and journal articles appeared asking what it meant to be a Japanese and what was Japan's distinctive role in the world. The Japanese called it the Nihonjin-ron, .. (p. 409).

The Japanese seem to be very aware of the importance of international or intercultural relationships. However, they have not realized that communication is something they could "study," and that the study of intercultural conmunication could enhance such relationships. The Japanese have developed their own ways for human interaction, but they tend to think successful cammunication can be achieved through exercising common sense. If they came to recognize the importance of studying communication for effective intercultural interaction, Nihon-ron or Nihonjinron could be used as a solid base for developing the field of intercultural communication. 


\section{B. PROBLEMS IN INTERCULTURAL COMMUNICATION}

As mentioned above, there is not much literature on intercultural communication which is written based on Japanese assumptions of reality or human nature. It is true that there are many studies on specific values or communication behaviors of the Japanese (Cathcart \& Cathcart, 1982; Morsbach, 1982, etc.). They are, however, mostly based on the Western approach to intercultural communication, and do not deal with basic questions such as what kinds of problems the Japanese are likely to encounter in intercultural interaction given their cultural assumptions. Because the Japanese assumptions of reality and human nature differ from those of Westerners, the potential problems in intercultural communication in the Japanese context are likely to be different from those discussed in the previous chapter. In this section, I will identify some potential problems for the Japanese in intercultural communication by using books and articles on Japanese culture and people.

The intercultural cormunication problems of the Japanese seem to be associated with differences between cultures, which is also the case in the Western approach. As will be discussed in Chapter Three, the Japanese in general assume basic human differences. So they are likely to recognize cultural differences sensitively. This assumption, however, leads them to create problems such as exclusionary attitudes toward foreigners, racial chauvinism and the tendency to rank cultures. The Japanese inclination toward relativism in ethics, which will be discussed later, seems to produce the problems of lacking a set of principles which hold true across situations. Finally Japanese formalistic or intracultural communication patterns seem to be problematic if they are 
used in intercultural communication.

\section{Exclusionary Attitudes}

The Japanese have a tendency to exclude outsiders or foreigners. They are reluctant to allow foreigners full participation in their society. Umesao (1976), for example, states:

Foreign students are almost never treated as individuals, but simple as non-Japanese unable to participate in Japan, which amounts to an insidious kind of discrimination (p. 23).

Such exclusionary attitudes discourage the Japanese fram cormunicating with people from other cultures, and are barriers to intercultural conmunication.

It is true that Japan has adopted and adapied many foreign ideas and things in its history. It is often said that the Japanese have a great deal of interest in and curiosity about foreign countries. However, their curiosity about foreign countries is limited. That is, while they are open to foreign ideas and things, they have very exclusionary attitudes toward foreign people. Christopher (1983) states:

Despite their readiness to adopt foreign ideas, institutions and techniques, most Japanese dont' welcome too much personal contact with foreigners ... (p. 57).

The exclusionary attitudes of the Japanese have been statistically demonstrated:

An opinion poll taken in 1980 showed that three out of four Japanese do not associate with foreigners and, what's more, don't want to (Taylor, 1983, p. 258).

Although cross-cultural study is necessary for comparison across cultures, the statistics seem to support the Japanese exclusionary attitudes.

Noticing a subtle difference between Japanese attitudes toward foreign cultures and those toward foreigners themselves, Hayashi (1977) points out that the Japanese have little face-to-face contact with 
foreigners in spite of their interest in and adoption of foreign cultures. He explains that this is because the Japanese want to maintain autonomous control over their acceptance of foreign cultures by interpreting those cultures in the ways which suit them. Such autonamous control is not possible in face-to-face communication with foreigners (pp. 193-194).

Clark and Takemura (1979) discuss a similar point. They contend that the Japanese tendency to perceive their identity in their immediate relationships explains their exclusionary attitudes toward foreigners. That is, the Japanese are exclusionary in the dimension where they pursue their identity while they are open in other dimensions. If they easily accept outsiders into their society, they might lose the meaning of their existence (p. 96). Thus, they need to keep foreigners away from their human relationships.

Tsurumi (1972) finds the source of these seemingly contradictory phenomena, the Japanese openness toward foreign cultures and their exclusionary attitudes toward foreign people, in Shamanism. She argues that Japanese society is characterized by the fact that Shamanism, which is supposed to be a primitive religion, is still alive today (p. 37) . She points out that one of the characteristics of Shamanism is its complete openness to things and ideas, and its exclusiveness about human relationships. She explains that this exclusiveness results from the fact that the rituals of Shamanism are conducted secretly by the Shaman and the people who believe in Shamanism (pp. 146-147). Thus, the ideas of Shamanism seem to direct the Japanese to exclude outside people while allowing them to take in new things and ideas from outside.

The exclusiveness of the Japanese is not limited to their attitudes 
toward foreigners. They have exclusive attitudes toward outsiders in their social life as well. Nakamura (1964) points out that "the Japanese attach great importance to a limited and specific human nexus," and maintains that exclusiveness and closedness are characteristics of such a nexus (pp. 488-489). Reischauer (1978) states:

Japanese are inclined to stick to already established group contacts and put all other persons into a well-defined category of "others" (p. 144).

As a result of their conmitment to a network of relationships with certain people, the Japanese tend to have exclusionary attitudes toward any outsiders, including other Japanese "outsiders."

Nakane (1972) also discusses the exclusiveness of a Japanese social group (p. 111). She differentiates three categories of people in terms of the way a Japanese perceives his or her society. The first category consists of those people with wham a Japanese works or spends most of his or her time. The second category comprises the people who exist in the extension of the first category. Most of the social life of a Japanese is spent with the people in the first and second categories. All the others are called strangers, who constitute the third category. People fram other countries belong to this category. Nakane emphasizes the importance of conmon experiences in the formation of the first and second categories. She points out that it is difficult for foreigners to have the first or second category-type relationships with Japanese since they rarely share a sufficient amount of common experiences with Japanese. She also says that complaints from foreigners that the Japanese do not treat them like other Japanese should be ascribed to the fact that the Japanese do not actively contact and make close relationships with people in the third category (pp. 1ll-1l6). 
Thus the Japanese tendency to value immediate human realtionships within their society explains their exclusionary attitudes toward any strangers. However, Reischauer (1978) thinks that their exclusiveness is especially strong toward foreign strangers. He states:

The Japanese sense of solidarity and exclusiveness is clearest in their attitudes toward foreigners in Japan. They take it for granted that foreigners are and always will remain foreign -that is, outsiders (pp. 404-405).

In short, the exclusionary attitudes of the Japanese seem to be a product of several elements. of Japanese culture such as values, beliefs and national or group identities. These elements seem to be all interwoven and deeply rooted in Japanese minds. The exclusiveness of the Japanese is clearly a drawback in intercultural communication. . It restricts the Japanese from initiating camunication with people fram other countries. It discourages foreigners from trying to understand and communicate with Japanese. Foreigners may even come to resist associating with Japanese at all after being rejected by Japanese repeatedly.

2. Racial Chauvinism

Closely related to the exclusionary attitudes toward foreigners is the rather strong conviction of the Japanese that they are different. They tend to believe that they are distinctively different from the rest of the peoples in the world. This tendency is problematic in intercultural cormunication. Reischauer (1978) points out that "the Japanese sense of being somehow a separate people--of being unique" is a barrier in Japan's relationship with the outside world (p. 401). This seems also true in the face-to-face interaction of Japanese with people from other cultures. 
The Japanese seem to find their distinctiveness in the Japanese race or tribe. Based on his observation of the tendency of the Japanese to say, "we, Japanese," in their conversation with foreigners, Kimura (1972) argues that the Japanese have a collective identity as the Japanese which transcends the level of individual identities. He contends that this phrase indicates the Japanese perception of themselves in association with Japan's long history and with blood relationships inherited from all of their ancestors in history. He reasons that this collective identity produces the exclusiveness and the feeling of separateness of the Japanese (pp. 10-12) .

Christopher (1983) describes the Japanese sense of distinctiveness using the term "tribe." He states that "the only way to win complete acceptance by Japanese is to be born into their tribe" (p. 49) . Even Japanese citizenship does not have significant meanings for being regarded as a Japanese. Christopher states:

. . , while it is possible--though not particularly easy-for a foreigner to acquire Japanese citizenship, it is not possible for an immigrant or the children of immigrants to "become Japanese" the way such people can "become American." .. - : you have to be born into the tribe. For that is what the people of Japan--or at least more than 97 percent of them--really are: members of a single great tribe united not just by cammon citizenship or cammon language but by common bloodlines, common racial memory and common tribal codes, same of which stretch back into prehistory (p. 51).

The Japanese tendency to perceive themselves as very distinctive seems to reinforce their exclusionary attitudes toward foreigners, which has been discussed above. But it also creates further problems in intercultural communication by leading Japanese to believe that they are so different that no other peoples in the world can ever really understand them. Clark and Takemura (1979) have observed that the 
Japanese are not willing to help foreigners in the study of Japanese human relationships, which is the key to understanding the Japanese people, while they are eager to introduce Japanese arts such as flower arrangement or traditional plays to the outside world. Clark and Takemura ascribe this selectiveness in introducing their culture to foreigners to the Japanese belief that foreigners will never fully understand them (pp. 108-109), a conviction Nakane also discusses (1972, p. 30) . Such a conviction will prevent Japanese from making themselves understood to the rest of the world.

Umesao (1976) calls Japanese culture the "radio receiver" type since it does not transmit, but only receives information. He maintains:

Japanese tend to be self-abnegating in their desire to understand others, but passive when it comes to getting others to understand them...., gathering information is accorded a positive value, while attempting to make the people of other countries understand the Japanese is actually thought to be less than useless, even negative (p. 27).

The passiveness of the Japanese in making themselves understood is likely to preclude the possibility of mutual understanding in intercultural conmunication.

The tendency of the Japanese to believe firmly in their distinctiveness can be labeled as racism. Reischauer (1978) states:

The Japanese concept of their difference from other peoples is not so much a matter of superiority, that is, of quality, but a difference in kind. They see themselves as being different not because tiney are better or worse than others but simply because they are different. In essence it is a deeply racist concept, almost as though Japanese were a different species of animal fram the rest of the world (p. 411).

Christopher (1983) also notes the discrimination practiced by the Japanese against Koreans, Chinese and Burakumin, a group of outcasts who were exiled to certain hamlets and only allowed to perform the most distasteful 
menial labor (p. 47).

Hori (1977) refers to a series of public opinion polls conducted fram 1958 through 1973. The polls show that the Japanese consider their own race to be superior to people of all other nations (p. 90). Christopher (1983) maintains that the Japanese, "in their hearts, feel superior to the rest of the world" (p. 57). This feeling of distinctiveness or superiority may be called racial or tribal chauvinisrn, and is a barrier when Japanese communicate with people of different racial backgrounds. They may distort the meanings of messages from those people or behave arrogantly toward them.

To summarize, the prevailing Japanese conviction that they are very different from other peoples creates difficulty in intercultural cammunication. The Japanese perceive their distinctiveness as centered in their race and exhibit discrimination toward other races. They may bring to the intercultural setting the preconception that foreigners will never understand them. Their racial chauvinism discourages mutual understanding and mutual respect.

\section{The Tendency to Rank Cultures}

While the Japanese tend to believe in their racial superiority, they do not necessarily consider their nation to be the best in the world. Instead of regarding Japan as superior to all countries, the Japanese seem to rank countries including their own. Their inclination to view countries in terms of some privately conceived national ranking system is likely to produce problems in intercultural communication. They may have either positive or negative attitudes toward people of other countries according to their relative standing in the ranking system. These attitudes may prevent Japanese fram genuinely understanding people from 
other countries.

Kano (1976) describes the Japanese sensitivity to ranking:

Psychologically, a Japanese tends to be insecure, uncertain of his ego-identity unless he can clearly define his relationship with others around him, his relative position in the community or the group(s) he belongs to. This tendency . . . creates a national hypersensitivity about international reputation and image. The Japanese preference for ranking and hierarchies is closely related to this particular psychological pattern and the social structure that has sustained it (p. 8) .

Reischauer (1978) observes:

... , the Japanese with their emphasis on hierarchy within their own society, tend to think of countries in a hierarchical order. All people do this to some extent, but the Japanese more frequently and more consciously than most. . . . , they do remain surprisingly conscious of their relative world standing in a number of statistical categories (p. 413).

Taylor (1983) also discusses the importance of hierarchy in Japan:

This love of hierarchy extends to nations and races. Japanese rank them unabashedly according to their "superior" or "inferior" qualities, and Japan's niche in the hierarchy is carefully monitored (p. 52).

Because of this tendency, the Japanese are generally interested in public opinion polls about other countries (Hori, 1977).

The Japanese tend to rank countries according to objective standards such as GNP, productivity and per capita income. Therefore, they are ready to accept that Japan is not superior to all the other countries. Reischauer (1978) points out "the Japanese readiness at most times to admit the superiority of at least some other country or countries" (p. 407).

As a result of their awareness of the relative standing of Japan in the world, the Japanese are likely to perceive and treat people of different cultures differently.

For this reason Japanese have absurd, unreasoning feelings of inferiority toward Americans or Europeans, but flaunt an equally unreasoning superiority and self-importance in the face 
of Southeast Asians or Africans (Nasu, 1978, p. 65).

Mestenhauser (1981) finds this tendency among Japanese students:

In my own study of the Japanese students' reactions to the foreign students in Japan, I am learning that they have different reactions, for example, to Koreans or other Asian and African students, than they do to the Americans and Europeans (p. 8).

The acceptance of the superiority of other countries seems to produce mixed feelings when combined with racial chauvinism. In other words, the Japanese have both superior and inferior feelings toward people fram countries ranked higher than Japan. While most Japanese seem to have an "inferiority complex" toward Westerners, they still harbor a belief, deep in their minds, in their racial superiority. The relative balance of the two kinds of feelings, superiority and inferiority, seems to vary from person to person. Regarding higher-ranked countries, some Japanese have very strong racial chauvinism without any feelings of inferiority, while some are very conscious of Japan's relative standing in the world and have feelings of inferiority with little racial chauvinism.

on the other hand, the Japanese feelings of superiority toward lower-ranked countries may be very strong because they are likely to be a product of the Japanese belief in both racial and national superiority. The Japanese inclination to rank countries and form superior and inferior feelings based on such rankings is problematic in intercultural canmunication. They may evaluate people of higher-ranked countries positively while judging people of lower-ranked countries negatively. Nakane (1972) points out that while the Japanese tend to admire anything fram European and American cultures, they often impose their own ways of doing things on less develogpd countries considering their ways superior 
to the local ways in every aspect (p. 37). Such preconceptions about a communication partner, whether they be positive or negative, are likely to distort the meaning of the message or behavior of the partner. From the moment that the partner's country of origin is known, the Japanese may be either ready to accept and conform to anything the partner says, or may be determined to reject or downgrade anything the partner cammicates.

\section{The Lack of Absolute Principles}

The Japanese behavior tends to be guided by relativism or particularism. This tendency has been singlea out by many scholars as one of the most important elements shaping Japanese culture. Lebra (1976) considers "social relativism" to be the Japanese ethos (p. 9). Similarly, Hamaguchi (1977) maintains that particularism-situationalism constitutes the ethos of Japanese culture (p. 32). The orientation of the Japanese toward relativism or particularism discourages them fram holding universalistic principles, which they could rely on across a broad scope of situations. This relativistic orientation may seem helpful for intercultural commication where it is useful to be flexible. But it may create problems because people without absolute principles are likely to suffer from information overload or identity diffusion in intercultural settings.

Nakane (1978) calls Japan "a country without principles." According to her, the religious beliefs or morals of the Japanese are not powerful enough to control their everyday behaviors. She maintains that Japanese life has never been governed by universalistic principles such as ethical systems (pp. 161-163). Mori (1977) also argues that the Japanese do not follow absolute principles in guiding their behavior. 
Christopher (1983) discusses a similar point:

Neither political ideologies nor formal religious creeds have the same absolute and unalterable grip upon most Japanese that they have on many Westerners (p. 55).

While Western ethics is based on universalistic principles, the Japanese tend to regulate their conduct according to the situational norms of human relationships. Reischauer (1978) states:

. . , there can be no doubt that the Japanese on the whole do think less in terms of abstract ethical principles than do Westerners and more in terms of concrete situations and complex human feelings (p. 140).

This difference seems to be manifested in the sanctions for bad conduct. Benedict (1946) characterized Japan as a shame culture, as opposed to the guilt cultures of the Christian west. The Japanese are so deeply concerned about the opinions and feelings of others that shame can be an important social sanction. Benedict states:

Shame is a reaction to other people's criticism. A man is shamed either by being openly ridiculed and rejected or by fantasying to himself that he has been made ridiculous. In either case it is. a potent sanction. But it requires an audience or at least a man's fantasy of an audience ( $p .223$ ).

The lack of absolute principles of the Japanese seems to be problematic in intercultural interaction, where they usually encounter a great deal of unfamiliar information from an unknown culture. They are likely to be distracted by too much uncertainty since they do not have clear directions to categorize the ideas and behaviors presented in that cormunication setting. It is difficult for them to maintain their identities because they lack the principles that define who they are across situations. Reischauer (1978) discusses this point:

One result of an ethical system oriented more to specific relationships than to abstract principles is that in an unfamiliar context it gives less clear guidance. When confronted by the unfamiliar, a Japanese is more likely to feel 
unsure of himself than a person who is smugly confident of the universality of his own principles. This is particularly true of a Japanese abroad, ... (p. 144).

Because of the lack of absolute principles and the value placed on human relationships, it is essential for Japanese to create and maintain relatively close reliationships in their immediate environments. This necessity is manifested in two extreme patterns of Japanese living overseas. Nakane (1972) describes the Japanese at one extreme who spend most of their time with the Japanese community in the local area, and the Japanese at the other extreme who turn their backs on the Japanese carmunity and assimilate into the local society. The Japanese who rely on a dense network of tangible human relationships will try to establish such relationships with local people when they cannot make contact with other Japanese in the area (p. 54). Clark and Takemura (1979) also find these two extreme cases to be typical of Japanese living overseas (p. 92) . It seems difficult for the Japanese to appreciate both Japanese and the host cultures in a foreign country. To a Japanese who perceives his or her identity in specific relationships, membership in two cultural groups is likely to result in two self identities, and psychological dilemma may result from the dual identities. It seems necessary for a Japanese to belong to only one group in order to maintain a stable identity. Furthemore, loyalty to only one group, whether it be a work group, a school group or a cultural group, is valued in Japan. Nakane (1972) has observed that only a few Japanese living overseas have contact with both Japanese and local people (p. 54).

5. Formalism or Imposition of the Japanese Communication Patterns

The Japanese have a strong tendency to stay with already established relationships and are not interested in making new relationships. This 
is a problem in itself, as has been discussed earlier. But there is another problem associated with this trait. That is, the Japanese are so accustamed to and comfortable with the communication patterns for their close relationships that they do not know how to communicate with people they know little about. This creates trouble in intercultural communication since they tend to be too formal with unknown communication partners or to impose their familiar communication patterns which are not appropriate for intercultural interaction.

The Japanese employ implicit, intuitive, nonverbal communication when they interact with their group members. Since they share a lot of cormon experiences and spend a great deal of time together, they need not verbalize much. Hall (1977) calls such implicit communication "a highcontext communication," which is "one in which most of the information is either in the physical context or internalized in the person, while very little is in the coded, explicit, transmitted part of the message" (p. 91) .

Explicit, verbal communication is considered undesirable by the Japanese. Reischauer (1978) maintains:

They have a positive mistrust of verbal skills, thinking that these tend to show superficiality in contrast to inner, less articulate feelings that are commicated by innuendo or by nonverbal means (p. 136).

on the other hand, indirect, implicit communication is respected. Ramsey and Birk (1983) state:

In the Japanese view, a good communicator can "sasshi ga hayai," or catch on quickly to another's meaning or desires before they are made clear and certainly before being logically conveyed. "Haragei" (hara-(belly)-gei-(sensitivity or subtleness) is often referred to, by Japanese, as the way of Japanese communication. It can be understood as heart-to-heart communication or the art of guessing inner thoughts by 
nonverbal means (pp. 245-246).

Such Japanese communication can be described as empathy. In fact, it has been pointed out that empathy is an important characteristic of Japanese interpersonal communication (Lebra, 1976; Stewart, 1980). The characteristics of Japanese communication discussed above apply to their intragroup cammication, but not to their conmunication with outsiders. Wagatsuma (1982) points out that the Japanese practice empathy among their group members while they tend to have negative feelings such as hostility or competition toward outsiders and strangers (p. 69). It can be said that the Japanese are so used to and comfortable with their intragroup communication that they will be at a loss when they neeci to communicate with unfamiliar people. Oshio (1982) states:

As for those with wham one does not even came into contact-complete strangers--while it is true that we Japanese are curious about them, we feel no desire to communicate with them, since at best any communication would be rudimentary compared with the subtle conmunication possible among the close-knit members of the family circle (p. 106).

The Japanese rarely have the opportunity to talk to and develop relationships with strangers. This is especially true with foreign strangers. The exclusionary attitudes of the Japanese, which have been discussed above, also reduce their chances to interact with strangers and foreigners.

Suzuki (1982) associates the difficulty of the Japanese in communicating with strangers with the Japanese language itself. He points out that pronouns and their equivalents in Japanese are selected based on the relationship of the speaker and the listener in each situation. In other words, the speaker ranks the listener in terms of the degree of intimacy, the age difference, the sex difference and the like, and determines his or her relative position to the listener. Suzuki thinks 
that the Japanese could not determine their positions when they face a person who they know little about or to whom they cannot apply their standards for detemining relative positions. He argues that the Japanese language is not very functional for interacting with strangers, especially with foreigners whose relative positions would be most difficult to locate (p. 126).

Thus, the Japanese tend to lack experiences with and skills for interacting with strangers, especially foreign strangers. It is likely that they will be at a loss in intercultural communication where they encounter unfamiliar people. Not knowing how to communicate with foreigners, Japanese are likely to employ inappropriate communication patterns. Nakane (1978) argues that Japanese usually employ formalized patterns for guiding their behaviors, instead of expressing themselves, in such communication. Formalism in communication is a defensive strategy, and is a helpful means to overcome the uncertainty which usually exists between people of different groups. Nakane points out that formalism in communication is the source of much of the foreigners' dissatisfaction with their interaction with Japanese (pp. 101-102) . Reischauer (1978) observes formality:

Japanese on the whole are less inclined than Westerners to enter into casual contacts and are likely to seem forbiddingly formal in any new encounter (p. 144).

Nakane (1972) maintains that the Japanese tend to impose their intragroup communication patterns when they are very enthusiastic about cormunicating with certain strangers. However, this does not usually work because they do not share common backgrounds with the strangers. Nakane maintains that this imposition of their familiar communication patterns on foreigners is one of the reasons that Japanese are disliked 
by the foreigners in spite of their good intentions (pp. 118-119).

Neither of the patterns, formalized communication or intragroup conmunication, is likely to lead to mutual understanding. The distance between Japanese and foreigners will stay large, and "real" communication will be impeded as long as the Japanese use the formalized conmunication patterns. The Japanese who impose their familiar intragroup conmunication patterns are not making allowances for cultural differences in communication styles, and are likely to arouse frustration and hostility in their communication partners.

To sumarize, five potential difficulties of Japanese in intercultural communication have been discussed. One of the problems is their exclusionary attitudes toward foreigners, which seem to prevent them from initiating interactions with foreigners. Another problem is the Japanese belief that they are distinctively different from the rest of the peoples in the world. This racial chauvinism discourages Japanese from making themselves understood to other peoples, and from achieving mutual understanding. Their tendency to rank cultures is also problematic because they are likely to evaluate people of other cultures either positively or negatively, which distorts their perception of those people. The Japanese in general lack absolute principles for guiding behaviors. This is a drawback in intercultural interaction since people without principles are likely to become unsure of their identities in unfamiliar situations. The last problem discussed in this chapter is the Japanese use of formalism or their intragroup communication patterns in intercultural communication. Both patterns are inappropriate for intercultural settings. Formalism will prevent "real" communication, and the use of Japanese intragroup communication does not accamodate cultural differences. 
CHAPTER III

CONTRAST AND COMPARISON OF WESTERN AND JAPANESE APPROACHES

TO INIERCULTURAL COMMINICATION PROBLEMS

As has been discussed, difficulty in intercultural communication arises out of various kinds of cultural differences both in the Westem approach and a Japanese approach. There seem to be, however, some differences between the problems of Westerners and those of Japanese. In this chapter, I will compare the Western approach and a Japanese approach to intercultural canmmication problems. First, I will discuss fundamental differences between Western and Japanese cultures which seem to underlie the differences in intercultural commmication problems between the two cultures. Next, I will examine whether the problems the Western approach focuses upon discussed in Chapter one are relevant or appropriate to a Japanese approach discussed in Chapter Two. In so doing, I will compare and contrast the characteristics of the problems of Westerners and those of Japanese. Finally, I will identify the problems which are peculiar to the Japanese.

A. FUNDAMENTAL CULTURAL DIFFERENCES BETWEEN THE WEST AND JAPAN

In his pioneering work, The Meeting of East and West, Northrop (1966) has pointed out a significant difference between Eastern civilization and Western civilization. On the one hand:

The oriental portion of the world has concentrated its attention upon the nature of all things in their emotional and aesthetic, 
purely empirical and positivistic immediacy. It has tended to take as the sum total of the nature of things that totality of immediately apprehended fact. . . (p. 375).

on the other hand:

What the West discovered is the existence of a factor in the nature of things, not immediately apprehended, which only theory can designate, and which only indirect verification through its deductive consequences can confirm or deny (p. 305).

While the Easterner appreciates immediate experience, "the Westerner is one step removed from experience" (Stewart, 1972, p. 25) . It is true that Westerners value empirical facts; however, they go beyond the factual stage, and pursue "the underlying laws and principles of which the direct experience of the Oriental observation is just an illustration." In Western civilization, "the process of abstraction and generalization" has been nurtured, and the capacity "to think in terms of absolutes and universal abstract principles" has been highly regarded (Peterson \& Shimada, 1978, p. 797). The Western mind has been concerned with the discovery of scientific laws which hold true under the same condition, in other words, with scientific universalism.

Developed in accordance with other Oriental cultures, Japanese culture is characterized by the emphasis on immediacy. Kishimoto (1967) maintains:

Inmediate experience plays a very important role in Japanese life. The Japanese people introspectively ponder and explore the domain of immediate experience. This is a very concrete domain for a Japanese. If conceptual speculation goes too far into abstract thinking, a Japanese quickly loses interest (p. 112). According to Kishimoto, two major religions in Japan, Shintoism and Buddhism "focus their main concern on the domain of inmediate experience" (p. 115) .

Having taken different routes of civilization, Westerners and the 
Japanese seem to differ in their construal of reality. It seems to be assumed in the West that reality--man, nature, and society--can be understood more by scientific theorization or logical reasoning than by direct observation or immediate experience. Northrop (1966) maintains:

Confronted with himself and nature, western man arrives by observation and scientific hypothesis at a theoretical conception of the character of these two factors. This theoretical conception, even when detemined by empirically and experimentally controlled scientific methods, always affirms more, . . . , than bare facts by themselves provide (p. 294).

Turner (1982) states:

Most theoretical perspectives in sociology operate under a number of assumptions: (1) Reality exists external to individuals; . . . (2) Through the development of abstract theory, the nature of the social world can be understood. (3) In trying to understand the social world, the contaminating influence of human senses and intellectual biases can be suspended by the application of the scientific method (p. 389) .

In a similar vein, Porter and Samovar (1982) state that in most Western thought "there is a belief that truth is out there somewhere, that it can be discovered by following the correct logical sequences" (p. 40). Westerners thus construe reality as discoverable through logic and science, and as existing external to human beings, whose sensory experiences does more harm than good to the discovery of such reality.

Inherent in that perception of reality is the assumption of a single absolute reality, which is universally valid. Bennett (1979) contends that there are two approaches to "single-reality" theory:

In this view, reality is not invented by our observational categories; it is discovered through either philosophical/ religious (idealist) insight or through objective (empiricist) observation. An indicator of the idealist approach to singlereality is some form of the statement, "If only we develop sufficient (wisdam, faith, knowledge, discipline, insight), we will know the true nature of the universe." An indicator of the empiricist approach is the statement, "We don't know it all yet, but with sufficient (experiments, categorization, 
instrumentation, explanation) we will figure out how things really work (p. 409).

on the other hand, the Japanese tend to take direct experience itself as reality. In Japanese culture, "Nature and society are accepted as they appear to the senses in their empirical immediacy" (Kawashima, 1967, P. 262). Peterson and Shimada (1978) state:

For the Japanese, the introspective observation of immediate experience is a positive and ultimately realistic point of view. An analytical or conceptual approach can proceed too far into abstract thinking and thus distort reality (p. 797).

The Japanese in general simply accept what is immediately experienced, or the phenomenal world, as it is. Nakamura (1964) maintains:

- . the Japanese are willing to accept the phenomenal world as Absolute because of their disposition to lay a greater emphasis upon intuitive sensible concrete events, rather than upon universals. This way of thinking with emphasis upon the fluid, arresting character of observed events regards the phenomenal world itself as Absolute and rejects the recognition of anything existing over and above the phenomenal world (p. 350).

Although the Japanese consider the phenamenal world to be absolute, they are at the same time aware of its fluidity, diversity, and, therefore, "indeterminateness." Kawashima (1967) contends that the Japanese value "the indeterminateness of Nature and society with immense variety and subtle nuances" (p. 262). Peterson and Shimada (1978) concur with his view:

. . . the Japanese mind is prepared to accept images of other individuals and society in general which are consonant with their infinite and inconstant variety of attributes as perceived directly by the senses. This indeterminateness of thought follows from the perception of reality through immediate experience .. ( (p. 798).

Thus, there are differences between Westem culture and Japanese culture in the fundamental perception of reality. Westerners assume that there is a single reality, which can be construed by scientific theories 
or abstract logical sequences. The Japanese, on the contrary, assume the world of their concrete experience to be real, avoiding too much abstraction. Such a world is inevitably indeterminate since it is perceived in terms of its inconstant variety of attributes.

This difference in the construal of reality seems to explain some of the differences between the Western and Japanese approaches to intercultural communication problems. Westerners, with their emphasis on the assumption of a single reality and universalistic theories, tend to assume that there is a basic human nature which transcends cultural boundaries. When they actively seek such a universal nature among all people, they are likely to try to perceive other people as similar to themselves. These are the problems of the assumption of similarities and the melting pot. The assumption of a single reality also leads Westerners to ethnocentrism; they tend to boast the superiority of their reality and to evaluate other views of reality negatively. Bennett (1979) argues that the assumption of similarity derives fram the assumption of a single reality, and that the melting pot and ethnocentrism are social consequences of these two assumptions (pp. 408-409).

On the other hand, the Japanese, with the value they place upon immediate experience, tend to emphasize a limited human nexus (Nakamura, 1964, p. 484). Because of this emphasis on their immediate human relationships, they tend to coasider themselves to be distinctively different fram the rest of the world and to exclude outsiders. These tendencies have been discussed as cultural chauvinism and exclusionary attitudes. The indeterminateness of the perception of reality leads the Japanese to be situational or relativistic in ethics. To them, each situation is different as it is directly perceived by the senses, and therefore should 
be approached aifferently. As a result, they lack principles which they can apply to any situation. In the next section, I will look at the differences and sinilarities between the Western and Japanese approaches to intercultural cormunication problens in more detail.

B. RELEVANCE OF THE WESTERN APPROACH TO THE JAPANESE CULTURAL CONTEXT

\section{The Assumption of Similarities}

In the Western approach, the tendency to assume similarities in behavior, values or thought patterns is identified as problematic in intercultural communication. Because of this tendency, people often ignore or negatively evaluate cultural differences. People tend to insist on the existence of basic human similarities while they are usually ready to accept some superficial differences. The tendency of Westerners to go beyond direct observation and seek universal underlying principles is in play when they try to understand the nature of human beings. They are ready to accept behavioral differences which they can directly see, but they tend to be persistent in their search for a basic human nature which is supposed to be shared by all people.

The assumption of a universal human nature, however, does not seem to be held universally. Taylor (1983) contends:

Americans believe, perhaps to a fault, that all peoples are basically the same and that with a little understanding and good-will, all apparent differences can be reconciled. Few Japanese believe this. For them, cultural and racial differences are intractable; the gulf that separates one people fram the next is at some level unbridgeable (p. 36).

The Japanese in general perceive and tolerate seeing individual differences among human beings. Because of their emphasis on direct experience through the senses, they do not try to generalize the qualities of 
different individuals or to find a basic human nature. Kawashima (1967) states:

In traditional Japanese culture, the individual is conceived as an existence which appears to the senses in its empirical immediacy-hence with an immense variety of attributes and subtle nuances (p. 274).

To the Japanese, the differences they observe among people through sensory experience are real. In the view that perceivable human differences are real, not superficial as Westerners often consider them to be, people are conceived of as fundamentally different. Hence, the Japanese generally assume that people are basically different.

In accord with the assumption of human differnces, the Japanese are usually aware of cultural differences as is shown in their cultural chauvinism and tendency to rank cultures. As discussed earlier, they tend to have a strong belief that they are distinctively different fram the rest of the world. They are also generally aware of differences among cultures, but mostly in terms of national ranking. The assumption of differences in certain rigid ways, rather than the assumption of similarities, tends to cause problems in intercultural cammunication by Japanese. At any rate, the Japanese are likely to bring to the intercultural communication situation the expectation that their partners will be different from themselves.

However, the Japanese may came to assume similarities in actual intercultural situations, in spite of their expectation to see cultural differences. For their awareness of cultural differences is mainly cognitive, and has been developed based on a great deal of information about foreign cultures available through books and other kinds of media, not based on actual face-to-face interaction with foreigners. As 
Hayashi (1577) points out, the Japanese rarely have opportunities to communicate with foreigners (p. 194). Although the number of foreigners living in Japan has been increasing recently, Japanese society is still a very hamogenous one with only a limited number of immigrants. Moreover, the Japanese tend to have exclusionary attitudes toward outsiders and are not willing to interact with them. But they have a great deal of interest in absorbing foreign things and ideas. As a result, their awareness of cultural differences is limited to the aspects of culture such as ideology, values, beliefs, custams and life style which can be learned fran books and other media.

Due to their limited experience of actual contact with foreigners, Japanese are generally not very aware of the ways in which different values or beliefs are manifested in the actual different behaviors of various cultures. Therefore, they may be prone to forming the assumption of similarities in cammication behaviors, in spite of their cognitive expectation to see cultural differences. They may assume similarities in the area of nonverbal behavior or in the thought patterns which direct verbal behavior. However, they are probably prepared to accept differences in those areas when they are pointed out, since they are predisposed to assuming basic human differences anyway.

The tendency of the Japanese to assume similarities seems stronger when they are eager to communicate with particular foreigners. In such a situation, they might even lose their awareness of fundamental cultural and individual differences among people. Nakane (1972) points out that the Japanese, when they want to accomplish samething actively with foreigners, take the position that they can get their message across if they show sincerity. And they often try to show sincerity by saying that 
people are all the same after all or that they should make friends with other Asians since they are the same Asians, while dismissing the assumption of human differences that they usually hold. Nakane argues that this position is the underlying assumption when Japanese impose their intimate communication pattern on foreigners, which has been discussed in Chapter Two. It seems important to add that Nakane says that the Japanese show this tendency to impose their way when they are enthusiastic (p. 119). The imposition of their intragroup conmunication pattern in such a situation seems inevitable since it is the only way they know of for communication besides the formalized patterns they generally use for avoiding "real" communication. The assertion that people are all the same might be just an excuse for needing to use their own cammunication patterns. When they seriously want to get a message across to foreigners, they may have to dispense with formalities and rely on their most familiar ways of communicating.

In short, the Japanese usually assume fundamental human differences, rather than blocking them out. But they may assume similarities at the behavioral level because of their lack of experience in interacting with foreigners on a face-to-face basis. The imposition of their intimate communication pattern seems to be an illustration of this tendency. Thus, the problem of the assumption of similarities as stated in the Western approach is relevant to a Japanese approach even though the Japanese generally assume differences among people.

\section{Ethnocentrism}

In the Western approach, ethnocentrism is recognized as a major source of problems in intercultural communication. This tendency to assert one's cultural superiority and to view all the other cultures 
according to one's cultural standards also seems to be problematic in a Japanese approach. Sakamaki (1967) points out that Japanese ethnocentrism is evident in the history of Shintoism. To take a few examples, Japan was once called "the Divine Country," or it was claimed that "the Japanese people by virtue of their direct genealogical kinship with the great divinities of the Shinto pantheon" possessed "the unerring instinct for proper conduct." And finally, Shintoism invoked "ethnocentric chauvinism" which led to World War II (p. 28-31). In a similar vein, Nakamura (1964) contends that "the boast that Japan was the best country in the wojold has existed fram very early times." He points out that "the notion of Japanese superiority is most boldly expressed in the concept of the Divine Nation" (pp. 434-435). Christopher (1983), however, maintains:

This superiority complex, if one can call it that, was deeply shaken by the debacle of World War II and has never since reasserted itself in the ugly guise it wore in the years before the war (p. 58).

Today Japanese ethnocentrism seems to be somewhat different from that of the past. The problems of racial chauvinism and the tendency to rank cultures discussed in Chapter Two seem to support this notion.

One of the characteristics of ethnocentrism in the Western approach is to divide the world into two parts, "us" and "them." As has been pointed out in the discussion on racial chauvinism, the Japanese generally have a sharp awareness of their difference from the rest of the world. They are, therefore, ethnocentric in terms of making distinctions between insiders and outsiders. In fact, Japanese ethnocentrism seems much stronger than Westerners' in this aspect. Reischaver 
The line between the "we" of the Japanese as a national group and the "they" of the rest of mankind seems to be sharper for them than for most peoples who participate much in international life. They appear to have a greater feeling of group solidarity and a correspondingly stronger sense of their difference from others (p. 401).

As discussed earlier, the Japanese tend to consider their limited human nexus to be absolute. This tendency leads them to believe that they are, as members of this special nexus, distinctively different from outsiders, and to exclude them. Their tendency to differentiate "us" and "them" is thus very strong. Compared to the Japanese, Westerners are probably less concerned with the "us-them" distinction since they tend to assume a single reality which transcends cultural boundaries. And because of the assumption of fundamental similarities among all people, they are generally ready to accept outsiders into their society. This "us-them" distinction is usually associated with the assertion of cultural superiority in the notion of ethnocentrism in the Western approach. The Japanese seem to have a double standard in determining superiority, one about races and the other about nations. These two criteria correspond respectively to racial chauvinism and the tendency to rank cultures, which have been discussed as problematic in a Japanese approach. The Japanese are generally very fim in their belief that they are racially superior to other peoples. Their assertion of racial superiority seems to be alternately restrained or reinforced by their awareness of the relative standing of their nation in the world.

On the one hand, the Japanese tend to have feelings of inferiority toward people fram the countries ranked higher than Japan, yet they are likely to retain a belief in their racial superiority deep within their minds. On the other hand, the Japanese are likely to have feelings of 
superiority toward people from the countries ranked lower, and to be very ethnocentric toward them because of the belief in both national and racial superiority.

In short, in Westerners' ethnocentrism, the distinction of "us" and "them" simply leads to the feeling of superiority of "our" culture and the denigration of "their" cultures. In Japanese ethnocentrism, the distinction of "us" and "them" does not necessarily lead to the belief in "our" cultural superiority. The Japanese assertion of cultural superiority is not straightforward; it is influenced by their consciousness of Japan's national ranking.

The Japanese awareness of their relative standing in various national rankings seems to affect the other aspect of ethnocentrism, the tendency to interpret and juage other people by one's own cultural standards. It is more likely that the Japanese will use the standards of the countries which they consider superior to Japan or those of the best country in the world for judging other countries, including their own.

Because the Japanese have a strong concern about social ranking, they tend to be very competitive about improving in the ranking. As they come to consider themselves as getting closer and closer to the highest of the national ranking, it is very likely that they will become more ethnocentric by shedding some of their feelings of inferiority toward certain nations. Christopher (1983) has observed this sign in Japanese politics:

. . it is only natural that Japan's present extraordinary achievements have left Japanese less disposed to humility now than they were in the '50s and '60s. Though on most occasions they remain by Western standards excessively polite and mired down in ritual courtesies. Japanese Government officials no longer automatically assume a low posture in 
their dealings with other nations (p. 58).

To summarize, the notion of ethnocentrism stated in the Western approach is also problematic in a Japanese approach. Racial chauvinism and the tendency to rank cultures characterize Japanese ethnocentrism, which seems to be somewhat different from Westerners' ethnocentrism. The Japanese tend to be much stronger than other people in the tendency to divide the world into two, "us" and "them." They present mixed feelings of superiority and inferiority in the aspect of asserting their cultural superiority. They are likely to use the cultural standards they consider to be superior to theirs for judging other cultures, including their own. Japanese ethnocentrism needs to be understood in this twofold framework. Only when once considers both racial chauvinism and the tendency to rank cultures, will one be able to comprehend Japanese ethnocentrism.

\section{The Melting Pot}

The melting pot, which claims that immigrants or minorities of a society should assimilate into the mainstream culture of the society, has been discussed as a problem in the Western approach. Being oriented toward abstraction and generalization, Westerners tend to assume a basic human nature which all people share, and a single reality which is true to all of them. This tendency encourages Westerners to believe that all the other people should participate in the same reality that they live in by adopting their proper ways. On the contrary, the Japanese, with the emphasis on their immediate human nexus, try to preserve the distinctiveness of Japanese culture. As discussed in Chapter Two, the Japanese tend to have exclusionary attitudes toward foreigners, which are totally opposed to the idea of the melting pot. While Westerners assert that 
minorities should assimilate into the dominant culture, the Japanese in general deny minorities' full participation in Japanese society. Prosser (1978) makes this contrast:

Many Americans think that their national cultural characteristics are so extraordinary that all foreigners wish to became Americans or to adopt our customs. It is true that a broad cultural adaptation of American customs and values has occurred in many cultures . . . On the other hand, in their ethnocentricity, the Japanese tend to think that their national cultural character is so unique that it can't be copied adequately (p. 1l) .

In short, the melting pot, which is problematic in the western approach, is neither appropriate nor relevant to the Japanese. The Japanese tend to discourage, not encourage, the assimilation of foreigners or imigrants into Japanese society. This tenciency, which is opposite to the melting pot view, is a problem in a Japanese approach. The exclusionary attitudes of the Japanese preclude their participation in intercultural communication.

4. Stereotypes and Prejudice

Stereotypes and prejudice seem to be problematic in a Japanese approach as well as in the Western approach. The Japanese are in general interested in and curious about foreign cultures. They have integrated many foreign things and ideas into their society, and are still searching for new information from cultures all over the world. However, in spite of their curiosity about foreign cultures, they seldam interact with foreigners because of the homogeneity of their society and their exclusionary attitudes toward outsiders. The Japanese, lacking face-to-face interaction with foreigners which may expose them to individual differences, have a tendency to form stereotypes about foreign cultures based on knowledge gained through books and other media. Stereotypes are thus relevant to a 
Japanese approach to intercultural problems.

After forming stereotypes about foreign cultures, the Japanese are likely to rank those foreign cultures according to the stereotypes. This tendency to rank cultures, a problem in a Japanese approach, seems relevant to the notion of prejudice in the Western approach. As discussed in Chapter Two, the Japanese tend to negatively evaluate people from lower-ranked countries, and tend to admire people from higherranked countries. These tendencies may be equivalent to the negative prejudice and positive prejudice mentioned in Chapter one.

The Japanese racial chauvinism also seems to be relevant to the issue of prejudice. Whereas positive prejudice may be reduced a bit by this feeling of Japanese superiority, negative prejudice against people fram lower-ranked countries tends to be reinforced by it. As mentioned in Chapter Two, discrimination against certain ethnic groups has been observed in Japan.

The problems of stereotypes and prejudice discussed in the Western approach are relevant and appropriate to a Japanese approach to intercultural commmication problems. The Japanese tend to form stereotypes because of their lack of experience of face-to-face interaction with foreigners. But the tendency to rank cultures, which seems to be a dominant component of Japanese prejudice, does not seem to be as pervasive in Western prejudice. The Japanese tend to form negative and positive prejudice according to the ranking of countries. Their racial chauvinism seems to reinforce negative prejudice toward people fram lower-ranked countries.

The intercultural communication problems of the Western approach discussed in Chapter one have been examined in terms of their relevance 
and appropriateness to a Japanese approach. The assumption of similarities is relevant to a Japanese approach in the behavioral aspect while the assumption of fundamental similarities is not likely to prevail among Japanese who are more apt to assume basic human differences. Ethnocentrism is also relevant to the Japanese. Compared to Westerners, the Japanese are very ethnocentric in terms of the "us-them" distinction whereas they have a double standard for asserting their cultural superiority and judging other peoples. The melting pot is an inappropriate concept in a Japanese approach. For the Japanese in general want to preserve their culture by limiting foreigners' participation in their society. Stereotypes and prejudice are relevant and appropriate to a Japanese approach. Like Westerners, the Japanese tend to form stereotypes and prejudice about other peoples, but they may base these on different groumds.

The problems in the Western approach which are not relevant to a Japanese approach, the assumption of fundamental human similarities and the melting pot, seem to be closely related to Westerners' assumption of a universal single reality. This problem is less likely to be associated with the Japanese, who are not interested in universal abstract thinking.

\section{INTERCULTURAL COMMUNICATION PROBLEMS PECLUTAR TO THE JAPANESE}

As discussed above, there are similarities in intercultural communication problems between the Western and Japanese approaches as well as differences; therefore, some of the problems in a Japanese approach can be categorized according to the Westem approach. Racial chauvinism can be called Japanese ethnocentrism. The tendency to rank cultures can be categorized as positive and negative prejudice. This tendency should 
also be considered as an important component of Japanese ethnocentrism. The imposition of Japanese communication patterns can be treated as the assumption of similarities in behavior.

The problems of the Japanese which seem to have less relevance to the Western approach are the problens of exclusionary attitudes towara foreigners, the lack of absolute principles, and formalism in communication. These three problems, which appear to be related to the Japanese perception of reality, may be of unique importance to a Japanese approach to intercultural communication problems.

Westerners may have a tendency to exclude outsiders like the Japanese because of the ethnocentric "us-them" distinction. But they seem to accept foreigners more readily than the Japanese. Being oriented toward the melting pot idea, Westerners tend to encourage foreigners or immigrants to assimilate into their societies. It seems that exclusionary attitudes are not critical intercultural problems for westerners. The problem of lacking absolute principles also does not seem to apply to Westerners, who tend to value universal principles for guiding their behavior. Formalism in communication is not very relevant to the Western approach either. Westerners seem to employ their normal cormunication patterns when interacting with foreigners, based on the assumption of similarities.

In this chapter, the Western and Japanese approaches to intercultural communication problems have been compared and contrasted. First, differences in the fundamental perception of reality between Western and Japanese cultures have been examined. Westerners tend to emphasize abstraction and scientific thinking, and to assume the existence of a single reality. The Japanese generally value concrete experience and 
consider their immediate human nexus to be most real.

Second, the problems in the Western approach are examined in terms of their relevance mainly in the behavioral aspect. Ethnocentrism is also relevant. The problems of racial chauvinism and the tendency to rank cultures should be taken into consideration for understanding Japanese ethnocentrism. Stereotypes and prejudice are relevant and appropriate to a Japanese approach. The Japanese seem to form prejudice based on national rankings. The problems of the Western approach which are not relevant to the Japanese are the assumption of fundamental similarities among all people and the melting pot, which are derived from the Western perception of reality.

Finally, the problems which are peculiar to the Japanese are identified. They are exclusionary attitudes toward foreigners, the lack of absolute principles, and formalism in communication. These problems, which seem to be derived from the Japanese perception of reality, are not likely to be serious problems for Westerners. 
CHAPIER IV

JAPANESE APPROACH TO IMPROVING INIERCULTURAL COMMUNICATION:

MODIFICATION OF WESTERR APPROACH

In this chapter, I will attempt to develop a Japanese approach to improving intercultural communication. I will discuss ideas, notions, and communication skills necessary for the Japanese to develop in order to improve their intercultural interaction. As discussed in Chapter Two, there is not much literature on intercultural communication from the Japanese point of view. Therefore, I will present a Japanese approach to improving intercultural communication mainly by using and mocifying suggestions and ideas fram the Western literature on this subject. First, I will discuss how the study of intercultural communication could be encouraged in Japan. This seems to be the necessary first step towara effective intercultural communication for the Japanese-a step which has already been established in the Western approach. Then I will consider whether the suggestions for improving intercultural conmunication in Western literature are relevant or appropriate in shaping a Japanese approach. Finally, I will present a Japanese approach to improving intercultural communication by summarizing the above two sections.

One thing needs to be made clear before proceeding. In the introduction of this paper, the goal of intercultural cammunication is defined as mutual understanding. This goal, which is set up based on the definitions of communication by Westerners, seems appropriate to the Japanese as well. In interpersonal communication among Japanese, the maintenance 
of harmony or good relationships is usually of prime importance. The Japanese tend to devalue explicit communication since it may create confrontation and destroy harmony. The Japanese with this tendency, however, do not dismiss the importance of understanding each other in communication. On the contrary, they value mutual understanding. As discussed in Chapter Two, understanding the other person even without having a clear message fram him or her is considered to be good communication. Such cammunication meets both the need to understand one another, and the need to maintain hamony.

As will be discussed in the following section, the Japanese may need to become more explicit in intercultural communication in order to achieve mutual understanding. In that event, they might not be able to keep harmony, at least on their side of conmunication. But it should be acknowledged that harmony may be viewed and sought differently in different cultures. Talking implicitly for fear of losing hamony on the side of Japanese ironically can create frustration or even hostility for conversational partners fram other cultures. The meaning of mutual understanding should involve the understanding of what is important to the communicators and how it is sought by them. Mutual understanding as the goal of intercultural comunication is also appropriate to a Japanese approach. The Japanese could seek harmony in an interculturally appropriate manner by making mutual understanding their first priority.

\section{A. STUDY OF INIERCULTURAL COMMUNICATION}

The first step that the Japanese need to take toward successful intercultural communication may be to realize the importance of the study of intercultural communication. As discussed in Chapter Two, the field 
of intercultural conmunication has not yet been established as an independent discipline in Japan. Although they are aware of the importance of international relationships in today's world, they have not fully recognized the study of intercultural communication as indispensable for improving such relationships. With only a few exceptions, the study of intercultural communication exists only to the degree that it is relevant to teaching English at universities in Japan. While recognizing the current use and application of intercultural communication in the instruction of English, Stewart (1980) maintains:

. . there is need for an understanding that intercultural cormunication, in its own full structural potential, has barely appeared in Japan. Yet the climate to the times clearly signals that the age of political and economic power is rapidly waning, replaced by the age of information and cormunication. The Japanese predicament in economics is the clearest of all of the signals of the caming epoch. The clear and present need in Japan is for a full understanding of the structure and process of its own patterns and conmunication, and of how well these operate in the national and the international spheres (p. 17).

One of the important ideas that the Japanese could learn from the Western approach is the assumption that intercultural communication can be improved through study and research on culture and communication. A major reason for the lag in the study of intercultural communication seems to be the Japanese resistance to the stuody of communication. As discussed in Chapter Two, the study of Japanese culture has been popular in Japan while the Japanese perception of self seems to have hampered the development of the study of communication. To the Japanese, who perceive their identities in their relationships with others, communication is an indispensable and intrinsic process which cannot be talked about abjectively. If intercultural communication is to be studied by Japanese, it needs to be studied in a way that would not require a major change in 
the Japanese perception of self identity. The way the Japanese conceptualize their existence is one of the core elements of Japanese culture, and needs to be taken into account when studying intercultural communication. The Japanese would probably become more motivated to study intercultural cormunication if the preservation of "Japaneseness" could be guaranteed.

In order to encourage Japanese to study intercultural carmunication, it seens necessary and important to differentiate the subject of intercultural communication from that of intracultural communication. It is the study of the latter which seems to arouse resistance among Japanese. As aiscussed in Chapter Two, Japanese generally derive their identities from their communication with others. Intracultural communication thus makes up the core of their cultural identity. The idea that intracultural conmunication could be a subject of study might bring about the fear of jeopardizing that identity. It should be emphasized to Japanese that intercultural communication, which requires new assumptions and skills, can be studied without changing the patterns of their intracultural communication substantially.

The study of intracultural communication could be pursued only for the purpose of providing the information necessary for the study of intercultural conmunication. Saral (1977) states:

- . same basic understanding of the process of intracultural camunication is a necessary prerequisite to developing, testing, and refining any exploratory hypotheses about various intercultural communication processes (p. 394).

The Japanese could maintain their identities through the study of intercultural communication by learning to confine their intracultural communication style to themselves and by developing a different communication 
style for the purpose of intercultural cormunication. The use of their usual communication pattern needs to be preserved for interpersonal communication among themselves to conserve the basis of their cultural identity. Japanese could develop new communication skills and patterns, which would allow them to retain their identities in the course of communication. When the study of intercultural cormunication is presented as developing a new communication style, not as improving or changing the original communication style, it may be accepted more easily by the Japanese.

The intercultural communication style probably should be different from the fomalized communication pattem the Japanese tend to use for communication with outsiders. Formalism in communication, as discussed in Chapter Two, is a barrier to intercultural communication since it discourages "real" conmunication or mutual understanding. The intercultural cormunication style should be intended to promote understanding between communicators. It should help Japanese make themselves understood to people of other cultures.

Hall (1977) differentiates two kinds of communication:

A high-context (HC) conmunication or message is one in which most of the information is either in the physical context or internalized in the person, while very little is in the coded, explicit, transmitted part of the message. A low-context (IC) communication is just the opposite; i.e., the mass of the information is vested in the explicit code (p. 91).

The communication style appropriate to intercultural communication seems to be a low-context communication. As Brislin (1981) points out, "much cross-cultural contact involves communicating with people who do not share the same types of information" (p. 59). It may be necessary to make the message explicit when the communication context does not provide 
the same information for the communicators. As discussed in Chapter Two, the Japanese communication pattern is a high-context one and thus is not appropriate to intercultural communication. The Japanese have a tendency to impose this pattern when they are eager to get their message across to foreigners. They could overcame this tendency by learning an explicit low-context communication style. In order to improve intercultural communication and to preserve the intracultural communication pattern, Japanese would need to shift back and forth between high-context and low-context communication styles.

Okabe (1983) emphasizes the necessity for the Japanese to verbalize messages. Naotsuka and Sakamoto (1981) point out that "if Japanese want to communicate with westerners they will have to modify their indirectness of expression and learn how to explain things to outsiders in words" (p. 180). While this suggestion seems to have been made because Westerners tend to be explicit in communication, it may also be effective when Japanese cormunicate with non-Westerners, who are generally highcontext communicators. Even if both parties, Japanese and other nonWesterners, are used to a high-context communication, they still do not share the same kinds of information. Therefore, a low-context style might be more appropriate to all intercultural communication.

The idea of developing a special intercultural communication style thus would seem to be helpful for the Japanese to solve the problems of formalism in communication and the imposition of the Japanese intracultural communication pattern on foreigners. This idea may also be useful for Japanese to overcome their exclusionary attitudes toward foreigners as it encourages the study of intercultural communication in Japan. As discussed earlier, the Japanese tend to exclude foreigners since they 
are afraid of losing autonomous control over themselves or of losing the meaning of their existence in the process of cormunication with foreigners. They could remove this fear and become more ready to participate in intercultural communication by studying this subject and developing skills specifically for interaction with foreigners.

Studying intercultural communication might even be an active way to preserve "Japaneseness." The Japanese might actually run a greater risk of losing their cultural identity if they keep avoiding interaction with foreigners. This passive means of maintaining the Japanese identity can only perpetuate intercultural problems. The resultant confusion in intercultural conmunication might disturb the Japanese self identity and ultimately bring about unexpected changes in the way the Japanese perceive themselves. As Umesao (1976) maintains, "to preserve our communication isolation will be to march down the road to extinction" (p. 31). The study of intercultural commication seems necessary to enable the Japanese to participate in today's international world without losing their "Japaneseness."

To summarize, the study of intercultural communication should be encouraged in Japan. It is important for the Japanese to learn from the Western approach that intercultural communication can be studied and improved. They could overcome their resistance to studying cammunication and the fear of losing their cultural identity by clearly differentiating the style for intercultural commuication from their everyday conmunication patterns. This style would be designed to promote mutual understanding and would be substantially different from the formalized communication the Japanese tend to use with outsiders. It would be a lowcontext cammunication, which is appropriate to intercultural communication 
where people do not share the same kinds of information. The Japanese need to switch from their high-context communication to this explicit style when they interact with foreigners. The study of intercultural communication may also help the Japanese to reduce and eliminate their exclusionary attitudes toward foreigners.

B. RELEVANCE OF THE WESTERN APPROACH TO THE JAPANESE CULTURAL CONTEXT

\section{Recognizing Cultural Differences}

In the Western approach, accepting and understanding cultural differences is considered to be essential for overcaming the assumption of similarities and improving intercultural cammunication. This prescription also seems important in the Japanese context since the Japanese have a tendency to assume behavioral similarities when they are enthusiastic about communicating with foreigners. Nakane (1972), after discussing the Japanese tendency to impose their communication pattern on foreigners, emphasizes the importance of recognizing cultural differences for developing good relationships with foreigners (p. 120). Inamura (1980) suggests that awareness of differences is one of the most important faculties for the Japanese to have in adapting to life in a foreign culture (208).

Although it seems important to point out cultural differences to Japanese, it should not be forgotten that they generally assume the existence of basic human differences, as discussed in Chapter Three. While Westerners tend to assume fundamental similarities as well as behavioral similarities, the Japanese are likely to assume similarities only at the behavioral level. They usually have cognitive awareness of cultural differences, but they may inadvertently assume similarities at the behavioral level in actual communication situations because of their lack 
of experience in intercultural communication. Therefore, it is important to stress the understanding of cultural differences in communication behaviors when designing a Japanese approach. The focus should be on how different values and beliefs are manifested in different behaviors across cultures and how people of different cultures communicate differently.

Cultural differences, however, should not be overemphasized to the Japanese. That might result in a contrary effect. As can be seen from their racial chauvinism, the Japanese have a keen awareness of their difference from the rest of the world. If cultural differences were stressed too much, the Japanese might became even more convinced of their distinctiveness and might totally give up on making themselves understood to foreigners. It seems important to suggest to Japanese that they are not the only people who are different from other peoples, but that all people aand all the cultures in the world are significantly different from one another.

\section{Cultural Self-Awareness}

The Western approach emphasizes cultural self-awareness for improving intercultural communication. When we realize the influence our own culture has upon us, we may learn to be more open to accept cultural differences and deal with them with less judgmental attitudes. Cultural self-awareness also seems important for the Japanese in resolving their difficulties in intercultural communication. The intercultural problems of the Japanese are rooted in their cultural attitudes, tendencies or behaviors. For solving those problems, it may be essential for Japanese to understand the ways in which their culture has conditioned the way they think and behave, and the mechanics of how it affects the way they 
deal with foreigners. Cultural self-awareness is also critical in helping the Japanese accept and understand the various ways people of other cultures think and behave, and to reduce evaluative attitudes toward them.

As has been discussed, the Japanese generally derive their identities from human relationships. Because they lack universal principles for maintaining their identities and guiding their behaviors, they are likely to feel insecure in unfamiliar cross-cultural situations. The vulnerability of their self identity seems to underlie the Japanese reluctance to study communication and exclusionary attitudes toward foreigners. It may be important for the Japanese to realize how their culture has taught them to perceive their identities in order to deal with the vulnerability of their identities effectively in intercultural cormunication settings.

The Japanese may need to understand themselves in dual dimensions. It has been pointed out that the Japanese have individual identities aside fram their identities as perceived in the human relationship, which usually overshadow the former. Lebra (1976) argues "the Japanese find their individuality in self-reflection, which can be fully enjoyed only in isolation." She continues to say:

Introspection leads the individual into his inner world and its center, kokoro ("heart"). His routine life, saturated in social involvement and preoccupation, is thus punctuated by an occasional confrontation with his kokoro. He expects to discover and rediscover his kokoro to be intact and autonomous from external pressures (p. $\overline{159)}$.

The duality of self identity seems to be manifested in two kinds of consciousness: tatemae and honne, well-known concepts among Japanese. Tatemae is a formal front or public stance, acceptable to others, and 
maintained for the sake of group harmony. Honne is a true feeling (Doi, 1982, p. 221). The Japanese usually take up the tatemae mode when they are with others while confining their honne to their inner world.

In order to avoid the feeling of insecurity about their identities in intercultural communication, the Japanese first need to realize their dual self identities and then shift to their individual states of consciousness or inner selves before entering into the intercultural communication context. Although the Japanese usually do not reveal their individuality in intracultural communication, it seems more advantageous for them to communicate based on their inner selves when interacting with foreigners. They would need to withhold their tendency to perceive their identities in human relationships when they communicate with foreigners. If they cammunicate from their individuality, they could probably preserve the relational identities in their immediate human nexus which they value so highly.

In the Western approach, knowing oneself is regarded as important for participating in intercultural interaction and this is directly related to cultural self-awareness. It seems especially important for the Japanese, who perceive their identities in human relationships most of the time, to understand who they are as individuals for the purpose of intercultural communication. Self-reflection before and after an intercultural experience might be an indispensable aid to the Japanese in retaining their inner selves. Inamura (1980) emphasizes that Japanese living overseas should have strong beliefs and attitudes of their own in order to adjust to a foreign culture effectively (p. 204). Although in Japanese intracultural communication, expressing or sticking to one's own beliefs is often frowned upon, it might be necessary to speak frankly 
during intercultural communication in order to preserve one's self identity. When one's inner self is maintained throughout the interaction, one can shift back to one's other identity existing in the human relationships.

In short, cultural self-awareness would be a critical component in a Japanese approach to improving intercultural communication. The Japanese would need to realize the impact their culture has had upon them in order to understand and resolve intercultural cammunication problems. They should also understand how other peoples have been influenced by their cultures, and overcome judgmental attitudes toward them. By developing self-awareness and knowing themselves better, Japanese could also resolve the problem of lacking absolute principles. In order to retain self identity throughout intercultural experience, it seems essential that Japanese understand the function of the duality of their self identities and shift to the individual identities before entering into intercultural interaction.

\section{Cultural Relativsim}

In the Western approach, the notion of cultural relativism is regarded as essential for effective intercultural communication. We need to stay away from the ethnocentric belief that our own way is the only right way, and to take on the relativistic view that no culture is better or worse than any other. This notion also seems important to the Japanese for overcoming their ethnocentrism, namely racial chauvinism and the tendency to rank cultures. The Japanese tend to view their race as distinctively different from and superior to other races. For effective intercultural communication, they should understand that other races are just as respectable as their own. Reischauer (1978) states: 
They (the Japanese) must overcame their sense of separateness and, to put it bluntly, show a greater readiness to join the human race. They must really identify themselves with the rest of the world and feel a part of it (p. 420).

The Japanese have a tencency to view cultures in terms of national ranking, and evaluate each culture either negatively or positively according to its relative standing in the world. For achieving mutual understanding, the Japanese need to restrain this tendency. They should accept the idea that all cultures are equally valuable regardless of their economic conditions or stages of technological development. Cultural relativism is thus a critical concept in a Japanese approach to improving intercultural communication.

\section{Pluralism/Multiculturalism/Multicultural Person}

In the Western approach, it is suggested that the melting pot should be replaced by pluralism or multiculturalism. In a pluralistic society, assimilation into the mainstream culture is not forced; instead, values and behaviors of different cultures are all appreciated. As discussed in Chapter Three, the Japanese usually do not hold the melting pot view; rather they seem to discourage foreigners' efforts to assimilate into Japanese society, and appear to try to exclude them from it. The notion of pluralism or multiculturalism, therefore, may not be relevant to the Japanese context. Although this notion could be used as a way to promote the acceptance of foreigners into Japanese society, it could bring about controversy in Japanese society.

The idea of pluralism, not to mention multiculturalism, seems very difficult to be accepted in Japanese society. The Japanese have valued the maintenance of their "Japaneseness," their cultural uniqueness, throughout their history. As mentioned in the introduction to this paper, 
the Japanese have never failed to modify foreign things and ideas when they adopted them. They have also emphasized the hamogeniety of their race in order to preserve "Japaneseness." Accepting other cultures into Japanese society without "Japanizing" them might affect the nature of Japanese culture itself. While promoting the idea of pluralism may be helpful for minorities in Japan, the issue of whether pluralism should be encouraged in Japanese society requires careful consideration of various matters and is beyond the scope of this paper. This issue is of great importance to the future of Japanese society, and needs thorough investigation in order to be discussed adequately. So the notion of pluralism or multiculturalism will be left untouched in this discussion of a Japanese approach to improving intercultural cammication.

The idea of becoming a multicultural person is also considered helpful for effective intercultural conmunication in the Western approach. While pluralism in Japanese society seems controversial, the idea of a multicultural person seems more acceptable. According to Adler (1982), "the multicultural person is psychoculturally adaptive," and for him or her, "attitudes, values, beliefs, and a world view are relevant only to a given context (p. 395). Such a person can smoothly adjust to Japanese culture, and will not jeopardize its "Japaneseness." Multicultural Japanese, who understand and appreciate other cultures besides their own, can contribute to mutual understanding between the Japanese and people of other cultures. They can also encourage the understanding of Japanese culture among people in the world.

The idea of becoming a multicultural person seems to be useful for Japanese living overseas. As discussed earlier, there are two extreme life patterns among Japanese living abroad: the complete assimilation to 
the host culture and the total involvement in the local Japanese conmunity. The Japanese with the tendency to perceive their existence in their inmediate human nexus usually find it difficult to keep membership in more than one culture. But they can overcome this difficulty and became bicultural or multicultural by understanding the duality of their identities and shifting bewteen the two modes of identity. With this technique they can take advantage of experiencing different cultures ana enjoy the diversity of the cultures. By becoming multicultural, they can promote mutual understanding across cultures and play an important role in the interface of Japanese and other cultures.

The idea of a multicultural person also seems useful for foreigners living in Japan. They should keep their identities firmly connected to their native cultures while adapting to life in Japanese society if they want to be accepted by the Japanese. The Japanese tend to have strong exclusionary attitudes toward those foreigners who attempt total assimilation into Japanese society, and who, therefore, seem to Japanese to be destroying "Japaneseness." Foreigners are likely to be accepted to Japanese society more easily if they show that they understand and appreciate their own cultures as well as Japanese culture, and are bicultural or multicultural.

To summarize, the notion of pluralism or multiculturalism in the Western approach will be left untouched in this exploration of a Japanese approach. This idea seems to have a large impact on the nature of Japanese culture, in which "Japaneseness" and homogeneity are valued. In this paper, the issue has been reduced to the idea of a multicultural person, which may be helpful in a Japanese approach to improving intercultural comminication. Bicultural or multicultural Japanese can play a 
significant role in promoting mutual understanding and help people of other cultures understand Japanese culture more readily. The idea of maintaining multicultural identity also seems useful for foreigners in Japan. The Japanese may reduce their exclusionary attitudes toward those foreigners who keep their own cultural identities while adjusting to Japanese culture.

5. Communication Skills

In the Western approach, developing cammunication skills is considered critical for improving intercultural cormunication as well as understanding the ideas and concepts described above. Three skills are discussed in Chapter one. They are empathy, nonjudgmental attitudes, and tolerance for ambiguity.

a. Empathy. Empathy is regarded as the most important cormunication skill for intercultural communication in the Western approach. By taking another person's point of view, one can really understand and appreciate cultural differences. Empathy also seems important for the Japanese in dealing with cultural differences. It is said that the Japanese generally employ empathy in their intracultural communication. The implicit communication pattern described in Chapter Two has been viewed as empathic cormunication. Lebra (1976) argues that empathy (amoiyari) is one of the indispensable virtues in Japanese culture:

omoiyari refers to the ability and willingness to feel what others are feelings, to vicariously experience the pleasure or pain that they are undergoing, and to help them satisfy their wishes. Kindness or benevolence becomes amoiyari only if it is derived fram such sensitivity to the recipient's feelings (p. 38) .

Stewart (1980) states that "when we consider societies where cultural norms of empathy prevail, we think of Japan" (p. 6). 
As discussed in Chapter one, empathy is a communication strategy effective for dealing with differences. Empathy should be distinguished from sympathy, which is useful for commmication where participants are similar to each other. When Japanese employ empathy in intracultural communication, they may not have to deal with significant differences among people for they generally share the same kinds of values, beliefs, and behavior patterns because of the homogeniety of their race and culture. When a Japanese tries to understand the different thoughts and feelings of another Japanese, the differences are usually within reach of his or her imagination. Probably, the line between sympathy and empathy in interpersonal communication among Japanese does not have to be drawn.

In intercultural interaction, empathy needs to be exercised for bridging distinctive differences among various types of people. Although the Japanese generally have the ability to use empathy, their empathy may not be effective enough for intercultural communication. They may have to develop another kind of empathy which can be used for dealing with a higher degree of differences in order to function well in intercultural commuication. While the Japanese are generally aware of cultural differences, they need to learn and understand in what ways people are different across cultures in order to develop such empathy, which is more appropriate to intercultural conmmication.

b. Nonjudgmental Attitudes. The withholding of judgmental attitudes during intercultural interaction is recommended in the western approach. As discussed earlier, the Japanese tend to judge people according to national rankings. While westerners generally judge others from their point of view, the Japanese have a tendency to evaluate people of other cultures based on the standards of countries ranked higher than 
Japan or ranked highest in the world. The Japanese are likely to evaluate people from higher-ranked countries positively, and to judge people from lower-ranked countries negatively. They should withhold their evaluative attitudes, whether they be negative or positive, for promoting mutual understanding across cultures.

c. Tolerance for Ambiguity. Tolerance for ambiguity is another important skill for effective intercultural communication in the western approach. Ambiguity is one of the major characteristics of Japanese interpersonal communication (Doi, 1982). It is a communication strategy developed for maintaining harmony and thus has an important function in Japanese society. The Japanese are generally prepared to tolerate ambiguity in communication. But the kind and amount of ambiguity presented in intercultural communication might be beyond their control since it usually involves unfamiliar cues from unknown cultures. They might be bogged down by information overload if they tried to tolerate all the ambiguity in intercultural communication. While a certain amount of tolerance for ambiguity seems necessary for effective intercultural communication, this skill may not have to be emphasized to Japanese, who already have it. Japanese might rather need to reduce their readiness to tolerate ambiguity in order not to get trapped by information overload.

In this section, the prescriptions for improving intercultural conmunication in the Western approach have been examined in terms of their relevance and appropriateness to a Japanese approach. The recognition of cultural differences, cultural self-awareness, cultural relativism and the idea of a multicultural person are relevant to and useful for the Japanese context though the characteristics of Japanese 
intercultural communication problems should be taken into consideration when applying these notions to the Japanese context. The notion of pluralism or multiculturalism does not seem very appropriate to a Japanese approach because of the nature of Japanese culture which emphasizes "Japaneseness." Among communication skills, empathy and nonjudgmental attitudes seem to be appropriate to a Japanese approach while tolerance for ambiguity seems irrelevant.

\section{JAPANESE APPROACH TQ IMPROVING INTERCULTURAL COMMUNICATION}

The goal of intercultural communication in a Japanese approach, as it is in the Western approach, is mutual understanding. The Japanese tend to focus on the maintenance of harmony in conmunication, but they could establish harmony more readily by making mutual understanding their first priority.

There is a prerequisite to a Japanese approach to improving intercultural cormunication. That is, the Japanese need to accept and understand the assumption that intercultural communication can be studied and improved. The study of this field should be encouraged in Japan.

As a Japanese approach to improving intercultural communication, this paper prescribes four notions and three communication skills, adapted from Westem intercultural communication literature. The four notions are the understanding of cultural differences, cultural selfawareness, cultural relativism and the idea of a multicultural person. The three skills are low-context communication, empathy and nonjudgmental attitudes. The encouragement of the study of intercultural commication and the above seven prescriptions are intended to solve potential intercultural communication problems of the Japanese. There should be more 
ideas and skills which are helpful for Japanese to improve intercultural communication. Further study will be necessary. 
CHAPTER V

\author{
APPLICATION OF JAPANESE APPROACH \\ TO INTERCULTURAL COMMUNICATION
}

Application has been a very important part of the field of intercultural conmunication, which "was built upon practical need" (Hoopes, 1979, p. 10). As Stewart (1980) points out, "the chief inspiration has been in applications" in the field (p. 2). In this chapter, I will present how a Japanese approach to intercultural communication can be applied in training in Japan. A Japanese approach is different from the Western approach, which it is based on, in terms of the kinds and characteristics of intercultural communication problems it addresses. This difference inecessitaces different treatments for solving the Japanese problems. Intercultural training for Japanese should incorporate these differences.

I will discuss how to integrate the ideas of a Japanese approach into the design of training in two areas, the intercultural communication workshop (ICW) as a university course and intercultural communication training in the business context. As has been discussed in Chapter Two, intercultural commmication has been taught as part of English instruction in Japan. But it should became an independent discipline in order to be taught more effectively. ICW may be one possible way to teach this subject. In the following section, I will discuss the ICW at Portland State University (PSU) and suggest modification so that it can be used appropriately and effectively at universities in Japan. 
Intercultural communication training has begun to be recognized as important among Japanese doing business internationally. Some training organizations have emerged to meet this need. I will look at the training program of one of those organizations, Fuji Xerox ICC Seminar, and suggest ways to apply the ideas of a Japanese approach to its program.

In discussing the two areas of training, one academic and the other business-oriented, I will focus on the content of the training, what should be included and emphasized. It is assumed that there should be differences in training settings or methods across cultures. Learning styles or educational systems need to be reviewed for such discussion, but that is beyond the scope of this paper. Although I will touch on some issues regarding the process of training such as learning behavior or self disclosure, further study will be necessary in this area.

\section{A. INTERCULTURAL COMMUNICATION WORKSHOP AT PSU}

Gudykunst and Hammer (1983) describe the intercultural communication workshop (ICW) as:

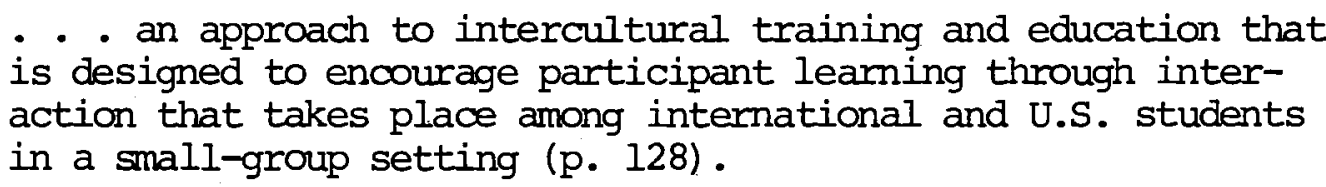

The ICW emphasizes experiential learning, as opposed to didactic learning, because "effective international understanding involves an attitudinalemotional component that can be acquired only through human interaction across cultural boundaries" (Scalzi \& Spring, 1975, pp. 55-56). According to Gaw (1979), "experiential learning provides activities that have the potential to involve the whole person in the educational process" (p. 147). The objective of the ICW is to increase cultural self-awareness, 
intercultural understanding, and acceptance or appreciation of cultural differences, and to improve intercultural conmunication (Clarke \& Hoopes, 1975, pp. 61-62).

The ICW at Portland State University (PSU) has been developed and directed by Milton and Janet Bennett. The course syllabus says:

The purpose of this course is to allow International and American students to learn about each others' cultures, and to improve cultural adaptation and intercultural cormunication skills. In the course, we will:

1. Discuss the basic concepts of intercultural communication;

2. Examine differences between American culture and other cultural behavior and values;

3. Explore different ideas about families, friendship, malefemale relationships, and other customs;

4. Learn communication techniques that are useful crossculturally.

In the ICW at PSU, the emphasis is on experiential learning except that a theoretical framework is provided through a lecture at the very beginning of the course. The students are expected to learn by participating in intercultural interaction in a small group setting, consisting of an about equal number of international students and U.S. students. The role of facilitators is to provide a non-threatening climate for an open discussion and help the students to learn concepts and skills of intercultural communication.

The ICW at PSU usually consists of ten sessions. In the initial meetings, an overview of intercultural communication is presented. It is made clear that aspects of subjective culture are the focus of this course. Verbal and nonverbal differences across cultures are discussed with examples. Then cultural value of orientations are explained. Stereotypes and prejudice are pointed out as barriers to intercultural communication. Ethnocentrism is described as a major source of intercultural problems. At the end, the notion of ethnorelativism or 
cultural relativism is introduced for effective intercultural communication.

In the second meeting, the students and facilitators meet for the first time as a small group, and get to know one another through an introduction exercise. The exercise commonly used is "mutual introduction." The group breaks down into pairs and after interviewing each other in a pair, each student introduces his or her partner to the group. Modeling by the facilitators helps the students get involved in the activity. Modeling is done in the rest of the sessions of the ION to introduce each activity.

The third session focuses on the Description, Interpretation, Evaluation (D.I.E.) exercise. The purpose of this exercise is to become familiar with the concept of separating those three stages, to become aware of the tendency to judge hastily, and to establish a nonevaluative climate for group discussion. After the introduction of the concept by the facilitators, the students practice using it for describing ambiguous objects and pictures and then apply it to their intercultural experiences. The topic for the fourth meeting is nonverbal communication. First, categories of nonverbal behavior are described and discussed for the purpose of increasing sensitivity to this aspect of communication. This is usually followed by role plays in which the students, in pairs, act out prescribed situations in mutually unintelligible languages. This exercise sheds light on cultural differences in nonverbal behavior. International students have a chance to demonstrate their bilingual abilities in this activity. An alternative to this role-playing is the discussion of how nonverbal behavior affects the way we perceive various situations. 
In the fifth meeting, cultural value orientations are explored. The distinction between general cultural tendencies and individual differences within a culture is explained first. Several exercises are suggested for this topic. In the "Shield" exercise, the students answer questions about their greatest achievements, beliefs or the like, written in the drawing of a shield. Then, they share one or two answers with the group. The facilitators help the students articulate their personal values, which can be inferred from the answers, and guide discussion of how personal values are related to cultural values. The topic of values can be approached deductively also. In ainother exercise, the five value orientations developed by Kluckhohn and Strodtbeck (1961) are used as a frame of reference. The students' personal values and their general cultural tendencies are explored in each of the five value orientations. The value contrast exercise in which opposite values are contrasted can be used as the second activity of this session. It helps the students understand how value differences lead to mutual negative evaluation in intercultural communication.

In the sixth meeting, the original large group gets back together to participate in a simulation called "BAFA BAFA." This simulation was originally developed by Gary Shirts (1973) for the U.S. Navy. Participants are divided into two groups, Alpha culture and Beta culture. Each group is taught a fictitional set of cultural values, behaviors and communication styles. The cultures then exchange observers and visitors; members of Alpha culture try to interact in Beta culture and vice versa. Participation in this simulation is followed by a debriefing of the experience. The discussion involves various aspects of intercultural communication such as culture shock, values, language learning, nonverbal 
behavior, stereotypes, prejudice and ethnocentrism. The students are required to write a midterm paper about this experience.

"BAFA BAFA" simulation leads directly into the topic of the seventh meeting, culture shock. The causes and symptams of culture shock are discussed. Then, coping strategies are explored. International students are encouraged to share their experiences. The concept of culture shock is treated as a learning tool for personal growth. When there is time left, the difficulty of returning hame after living abroad is discussed since many intemational students plan to go back to their home countries.

In the next two meetings, some cultural topics such as friendship, male-feriale relationships and family structure are explored with the focus on cultural differences in these areas. The concepts from the previous meetings are integrated into this discussion. The students have usually become open to talking about the customs or habits of their native countries. A nonjudgmental climate has often been achieved by this stage of the IW, which is important for discussing cultural differences.

In the final session, the "Famous Artist" exercise is used for wrapping up the whole course. In this exercise, the students draw a picture of the images of the group members or of the developmental process of the group. The students have been directed to focus on the content of the discussions in previous meetings, but they have a chance to look at the group process in this final session.

Throughout the course, the students are required to write in their journals after each meeting and submit them to the facilitators for comment. In their journals the students can express their feelings about the meetings or talk about personal experiences which they did not have a chance to discuss in the meetings. In addition, a final paper involving 
an analysis of a cross-cultural interview is required.

B. MODIFICATION OF ICW AT PSU FOR JAPANESE CONTEXXT

The idea of the ICW may not be easily accepted or understood by the Japanese at first because of its structure and setting which are unfamiliar to them. Nevertheless, the ICw can be very useful for Japanese in improving their intercultural communication if the content is modified appropriately. As discussed earlier, Japanese rarely have opportunities to interact with foreigners because of the homogeneity of their society. Their exclusionary attitudes toward foreigners further reduce actual intercultural contacts. As a result, they lack conmunication skills for intercultural interaction, and tend to use inappropriate communication patterns, which discourage mutual understanding. The ICW as presented at PSU can provide Japanese with experience in interacting with foreigners and can help them develop effective intercultural skills. In this section, I will suggest ways to modify the ICW at PSU for the Japanese context.

One problem is that the number of universities which accept foreign students is limited in Japan. Umesao (1976) points out that "Japanese students who go to other countries outnumber by far the foreign students who come to Japan" (p. 27). At present, only certain large universities could create a class in which half of the members were international students as in the case of the ICW at PSU. But establishing intercultural communication courses may increase the participation of foreigners in universities in Japan, and may contribute to a better understanding of Japanese culture by foreigners. The universities which have intemational students should take full advantage of having them 
and provide courses in intercultural communication.

Experiential learning used in the ICW at PSU should be appropriate to the Japanese students if it is true that immediate experience is valued in Japanese culture, as discussed in Chapter Three. However, the Japanese students are usually more accustamed to passively listening to lectures than to actively participating in activities or exercises. As for discussion, they are generally more concerned with the maintenance of harmony than with the honest sharing of their feelings or opinions. Japanese students, therefore, may feel uncomfortable with participating in an ICW.

However, having to participate actively in an ICW can be a way to develop a low-context communication style, which Japanese need to leam for effective intercultural communication. And young Japanese students who have been exposed to Western culture may find it less difficult to express themselves verbally than older Japanese.

In the Japanese ICW, it seems essential that facilitators be carefully chosen. This is true with the ICW at PSU also. But the importance assumes more importance in the Japanese ICW when the reserved attitude of Japanese is taken into consideration. The facilitators should have a very good understanding of the modest and indirect communication behaviors of the Japanese, as well as of the communication styles necessary for intercultural conmunication. They need to help the Japanese students develop the latter. They should create a good rapport so that the students can feel comfortable sharing their opinions and feelings. They must also emphasize that their role is different from that of teachers, who are usually authoritative in Japan.

In the Japanese ICW, participating without talking, but through 
listening should be accepted, especially in the beginning of the course. In an ICW in Western culture, which values verbal skills, participation neans verbal participation. In Japan, the mere presence of a person at a meeting, for example, can mean participation. He or she may be there to listen and gather information. To Japanese, listening is a very important aspect of communication. The facilitators should understand this value and allow quiet students to learn in their own ways, by listening, until they become ready to participate verbally.

In terms of the setting of the ICW, the Japanese tendency to rank cultures discussed above might be a problem. Because they have different attitudes toward differently-ranked countries, they may find it difficult to deal with people from higher-ranked countries and people from lower-ranked countries in the same situation. But this difficulty is one of the things that Japanese should work toward overcoming through the course of the ICW. When the ICW consists of people from various countries in terms of national ranking, the Japanese tendency to rank countries should be brought up early in the course. For example, it should be presented in the D.I.E. exercise in winich students learn to withhold judgmental attitudes.

The first session of the ICW at PSU is a lecture. In the Japanese ICW, a lecture should also be given to introduce the field of intercultural communication to the students. The content of the lecture of the ICW at PSU would need to be modified for the Japanese context. After describing the concept of intercultural communication, the lecturer should explain intercultural camminication problems of both Japanese and Westerners, and point out the cultural differences in their problems. Then the ideas and skills that help us overcome those problems should be introduced. 
As has been discussed above, the idea of studying communication is not necessarily positive to Japanese. The Japanese students in the ICW may have some resistence to the study of intercultural communication. In the lecture, it should be made clear that improving intercultural communication skills and attitudes does not mean changing or jeopardizing one's cultural identity or culturally unique communication behavior. The students should know that they will learn a new set of attitudes and skills in order to interact successfully with people from other countries, while keeping their intracultural communication patterns intact.

The introduction exercise in the second session of the ICW at PSU also seems necessary in the Japanese ICW. But the Japanese tend to be very hesitant to talk about themselves to new acquaintances. Gudykunst and Hanmer (1983) point out that "the U.S. skill of 'self disclosure' may be viewed in Japan as 'loss of face'" (p. 124). Barnlund (1975) has found that there is substantially less self disclosure among Japanese than there is among Americans. The technique of "mutual introduction" may be better than self introduction in that the students have a chance to talk about themselves in a pair before being talked about to the whole class. But this still requires self disclosure. It will probably be useful in this session to direct the students to share very general information about themselves and their cultures. The facilitators can avoid making the students uncomfortable by limiting the kinds of questions they can ask their partners in the interview. As the ICW goes on and the students get used to the class, they may become more open in sharing their personal opinions and feelings.

The D.I.E. exercise in the third session of the ICW at PSU seems to be an important exercise for Japanese students as well. They should 
understand the importance of separating the three stages of description, interpretation and evaluation. Then they should discuss what they base their judgment on. The Japanese orientation toward situationalism should be contrasted with the Western inclination toward universalism. After the students come to grasp the notion of D.I.E. and the nonjudgmental attitudes that go with it, they should be made aware of the Japanese tendency to evaluate other countries based on their national rankings. They should recognize how the Japanese in general tend to evaluate people either positively or negatively depending on their country of origin. This is a very sensitive issue. It may be less threatening to the students to discuss this subject as a general tendency of the Japanese, avoiding talking about the individual students' perception of people of different countries.

The fourth and fifth topics of the ICN at PSU are nonverbal cormunication and value orientations respectively. This order is based on the assumption that cultural differences in nonverbal behavior may be easier for American students to understand and accept than cultural value differences. As discussed earlier, Westerners with their assumption of basic human similarities tend to resist the idea of the existence of fundamental cultural differences among people in the world while they are more ready to accept superficial differences such as differences in nonverbal behavior.

In planning the Japanese ICW, it seems appropriate to reverse the order. The Japanese, who tend to assume basic cultural differences, are likely to understand cultural differences in values without much difficulty. But they are usually not very aware of behavioral differences because of their lack of experience in communicating with foreigners. It 
is likely that they will understand behavioral differences more easily after the discussion on fundamental value differences.

Therefore, in the fourth meeting of the Japanese ICW, value orientations should be explored. In the ICW at PSU, both cultural and personal values are discussed. But in the Japanese ICW, cultural values, the values generally shared by a people as a culture group, should be focused on while personal values, which are held by each individual, are left out. For, as mentioned earlier, the Japanese tend to feel uncomfortable about self disclosure in their initial contacts with people. Their personal values can be explored when they discuss cultural topics later in the course. The "Shield" exercise which deals with personal values should be avoided at this stage of the course. General values in cultures can be discussed based on the five value orientations developed by Kluckhohn and Strodtbeck (1961). The value contrast exercise, which sheds light on how each culture conditions its people to believe and value certain things to the exclusion of others, can be used to describe Japanese ethnocentrism, consisting of racial chauvinism and the tendency to rank countries, as well as ethnocentrism in general. At the end of the fourth meeting, the notion of cultural relativism and the communication skill of empathy should be introduced as means of overcaming intercultural communication barriers.

In the fifth meeting, nonverbal communication should be explored. This topic is important to Americans since they are usually not very aware of the nonverbal aspect of communication because of the value they place on verbal skills. For the Japanese ICW, the topic should be expanded. Besides the discussion on cultural differences in nonverbal behavior, the relative importance of the two modes of communication, verbal and 
nonverbal, in different cultures should be discussed. Then the distinction between high-context and low-context communication styles should be explored. The Japanese tenciency to use formal cormunication or to impose their high-context communication style in the interaction with foreigners needs to be pointed out. Developing a low-context cammunication style for the purpose of intercultural canmunication shoula be encouraged, but this process takes a lot of time and probably requires another university course.

The simulation, "BAFA BAFA" in the sixth meeting of the ICW at PSU also seems appropriate in the Japanese ICW. This simulation may give the Japanese students who lack intercultural experience a more concrete idea of how it would be to interact with foreigners or to live in a foreign country. The issue discussed in the previous sessions such as conmunication styles, values and ethnocentrism can be reviewed in relation to this exercise.

The topic of culture shock seems also important for the Japanese students to discuss after the BAFA BAFA session. The international students should be encouraged to talk about experiences in Japan. If they are a mixture of people from differently-ranked countries, it may be interesting to discuss if they have been treated differently in Japan. But this is a sensitive issue and can be discussed only when the group is sufficiently cohesive.

In the eighth meeting, the issue of self identity should be dealt with. This topic, which is incorporated in the culture shock session in the ICW at PSU, seens to need more attention in the Japanese ICW. For the Japanese self identity tends to be more vulnerable in intercultural experience tiran the Western self, as has been discussed in Chapter Two. 
It should be pointed out that the Japanese tend to find their identities in their immediate human relationships, not in abstract principles. The two extreme cases of Japanese living overseas may be described to clarify this point. Then the duality of the Japanese identity should be explored in relation to the notion of cultural self-awareness. It should be suggested that it is important to shift to the individual identity for the purpose of intercultural communication while keeping the group identity for interpersonal relationships in Japan. Finally the notion of a multicultural person should be introduced. This notion can be used by both the Japanese students and international students. As explained in Chapter Four, a Japanese multicultural person can contribute to mutual understanding among people in the world while keeping his or her own cultural identity. A foreigner, by being a multicultural person, can live harmoniously with Japanese. In Japan, how to be an internationalist has become an important topic recently. A multicultural person could be one model of the internationalist.

In the next sessions, same cultural topics would be discussed as in the case of the ICW at PSU. Cultural differences in various topics such as friendship and family structure can be explored. At this stage of the course, the students may be able to share their personal opinions and feelings more freely than in the beginning.

In the final session, the "Famous Artist" exercise can also be used in the Japanese ICW. In the ICW at PSU, the images of the group members or of the developmental process of the group are supposed to be drawn. These topics seem fine with Japanese students. But I would suggest that another topic such as the image of a multicultural person should be added. For some Japanese may feel uncomfortable drawing a picture of their group 
members or group as a whole, worrying if their picture might offend somebody's feelings because of the value of harmony.

The students in the Japanese ICW should also keep a journal after each session and submit it to their facilitators. Writing about personal experiences is encouraged in the ICW at PSU, but the facilitators in the Japanese ICW might have to wait some weeks before the Japanese or other Asian students come to feel comfortable talking about their personal opinions and impressions.

The basic design of the IOW at PSU could be applied to the Japanese ICW. But the application requires same modification in the kinds of exercises and a shift in emphasis regarding certain topics. The intercultural cammunication problems of Japanese and strategies to cope with those problems should be integrated into the design of the Japanese ICW.

\section{FUUI XEROX INTERCULTURAL COMMUNICATTON SEMINAR}

Fuji Xerox Intercultural Communication (ICC) Seminar, which is held at Fuju Xerox Co., Lta. in Tokyo, Japan, has been built to promote a better understanding of communication between Japanese and Western cultures. It provides training for developing attitudes and skills necessary for successful intercultural communication, especially in business setings. The programs offered by this seminar were originally designed by Intercultural Relations Institute (IRI) International, located in Redwood City, California, based on its experience in counseling and training activities in the field of intercultural communication. The trainers, who are sent from IRI, have educational background and ample real-life experience in intercultural communication between Americans and Japanese. Fuji Xerox ICC Seminar offers six courses: A, B, C-1, C-2, C-3, 
and C-4 for Japanese businessmen. Course A is called Culture Awareness Seminar. It is designed to explore the cause of communication problems in doing business with people of different cultures, and to promote adaptability to culturally different business environments. Trainees will explore differences between Japanese and Western cultures in various areas such as values, custams and social rules through watching videos and discussing their personal experiences in international business. Then they will inquire into the cause of misunderstanding, conflict or mutual distrust in communication between Japanese and American businessmen. The simulation game, BAFA BAFA, described earlier, is also used in Course A for the understanding of culture shock. The stages of cultural adaptation are explained. Then the trainees will learn skills and attitudes for effective intercultural communication. The concept of cormunication styles is introduced. The trainees will learn the importance of learning different kinds of communication styles for success in intercultural cormunication. But developing skills is not the main focus in Course A. It is extensively dealt with in the other courses. Course B is called Basic Skills Seminar. It focuses on the development of the skills for intercultural communication. Trainees will first learn the key concepts of intercultural communication such as culture shock, cultural adaptation and communication styles. Then they will practice intercultural communication skills, which are categorized into four modules: Interactive Listening, Lubricant Expression, Maintaining Conversation and Oral Presentation. These four modules can be learned separately by taking courses $\mathrm{C}-1, \mathrm{C}-2$ and $\mathrm{c}-3$.

The Interactive Listening module is designed to understand the differences in listening behaviors between Japanese and Westerners and to 
build effective listening skills for communication with English-speaking people. While the Japanese generally consider listening as a passive behavior, Westemers expect the listener to take the initiative in obtaining clarification from the speaker when the message is not clear. Trainees will learn how to interrupt the conversation, check difficult experssions and confinm what the speaker has said. This module alone makes up an independent course, C-l, Interactive Listening Skills Seminar. The Lubricant Expression module focusses on expressions for facilitating smooth daily conversation. Trainees will learn the greetings, conversational formulas, and other expressions which lubricate interpersonal relationships with English-speaking people.

The Maintaining Conversation module is designed to develop the skills to sustain and enjoy conversation. Trainees will learn both verbal and nonverbal skills to open, maintain, and close a conversation with English-speaking people in pleasant ways. This module combined with the Lubricant Expression module makes up Course c-2, Maintaining Conversation Skills Seminar.

The Oral Presentation module focuses on how to make an oral presentation in English. It is designed to develop practical skills for effective presentation in front of English-speaking audiences. Persuasive skills are especially emphasized. Trainees will learn the important elements of presentation such as the coherent organization of presentation content, the appropriate speed of speech, and gestures. This module makes up C-3, Oral Presentation Skills Seminar.

Course C-4 is Meeting Management Skills Seminar. This course is intended to develop practical skills necessary for the effective management of meetings conducted by people fram different cultures. Trainees 
will learn the differences between Japanese-style and Western-style meetings in terms of expectations, objectives and procedures. Conflict in bicultural meetings is discussed with the focus on the differences in resolving conflicts between Japanese and Western cultures. Then multicultural meeting management skills are introduced and practiced.

In courses $\mathrm{B}, \mathrm{C}-1, \mathrm{C}-2$, and $\mathrm{C}-4, \mathrm{a}$ variety of training methods are used. They include discussion of films and personal experiences, roleplays and a simulation game.

\section{MODIFICATION OF FUJI XEROX ICC SEMINAR}

One of the strategies for effective intercultural cormunication that a Japanese approach to intercultural conmunication recommends, namely developing low-context communication styles, seems to be incorporated very extensively in Fuji Xerox ICC Seminar. Course B, and Courses C-1 through C-4, which focus on communication skills, seem to provide sufficient training on the development of low-context commuication skills in various situations. Although course A does not involve skillbuilding training, it still touches on the importance of developing altemate communication styles. The Interactive Listening module encourages Japanese to make conmunication explicit from the listener's point of view. The Lubricant Expression and the Maintaining Conversation modules help Japanese get verbal communication going smoothly. The Oral Presentation module, which focuses on persuasion, teaches Japanese how to express themselves explicitly and assertively. Finally the Meeting Management Seminar deals with low-context interaction in the process of a meeting. Some of the ideas of a Japanese approach could be applied to Course A, Culture Awareness Seminar. The intercultural communication problems 
of the Japanese could be explained and discussed in comparison with those of Westerners. It would be useful for Japanese trainees to understand the potential problems of both sides of intercultural communication. The Japanese tendency to exclude foreigners could be pointed out in the beginning of the course since this topic suggests the importance of taking this course. In the debriefing session of the simulation game, BAFA BAFA, Japanese ethnocentrism consisting of racial chauvinism and the tendency to rank cultures could be talked about. The mixed feelings of superiority and inferiority toward Westemers held by many Japanese could also be discussed in this session. In the discussion of cultural adaptation, it would be important to point out that the Japanese tend to lack universal principles which could be helpful in cultural adaptation. The two extreme cases of Japanese living overseas could be mentioned as an illustration of this point. When the concept of communication styles is introduced, the differences between high-context and low-context communication styles would need to be explained. The Japanese tendency to use either their intracultural cammication styles or formalized patterns should be discussed as problematic in intercultural comminication. In the discussion of improvement of intercultural communication in Course A, suggestions from a Japanese approach could also be applied. It should be explained to Japanese trainees that the study of intercultural communication could be achieved without much change in intracultural communication, which they might be afraid of losing. In the discussion of cultural differences, it seems important to point out that cormunication is possible in spite of the existence of differences across cultures. For Japanese tend to think that they are so different from the rest of the world that no other people will understand them. The notion of 
cultural relativism should be introduced as an alternative attitude. Course A seems to aim at the development of cultural self-awareness. The duality of the Japanese identity should be pointed out and explored through the process of becaming aware of the influence of a culture upon its people. It should be important to suggest that Japanese could shift to their individual identity mode for the purpose of intercultural communication. After the topic of the duality of Japanese identities, the idea of becoming a multicultural person should be discussed. Since Fuji Xerox ICC Seminar is built around the concept of an effective international businessman, it would be very appropriate to present the model of a Japanese multicultural person. It should be discussed how it is possible to become multicultural while keeping "Japaneseness." It seems appropriate that course A emphasizes the importance of developing explicit communication styles. This leads to the content of the other courses, which provide training for practical communication skills.

An attempt has been made to apply a Japanese approach to intercultural communication to Fuji Xerox ICC Seminar. The seminar seems to be both effective and appropriate for Japanese trainees. The ideas of a Japanese approach could be integrated into course $A$ in order to make it more relevant to the Japanese context.

In the above section, two training areas for intercultural communication have been discussed to show how a Japanese approach could be applied. There seems to be more areas where ideas of this approach could be used. One such area would be orientation for Japanese students coming to colleges in the United States. Some organizations which handle the arrangement for people studying abroad offer pre-departure meetings for them. But these meetings usually provide mere information and do not 
give much consideration to how the students could successfully adjust to foreign social environments. Training could be set up to help students understand their potential problems in acculturation and develop ideas and skills for coping with them. A Japanese approach could be used in such training. It could provide concepts and ideas appropriate for Japanese trainees.

Another possible area of the application of a Japanese approach would be training for Americans who have interaction with Japanese. They could be Americans who are going to Japan on business or for stuây, or who have communication contact with Japanese in this country. Naturally the Western approach would be suitable for Western trainees. However, a Japanese approach could also be integrated into training. Americans could benefit from studying both approaches in their attempt to improve communication with Japanese. Their effort to solve problems identified only by their side of cammunication might not lead to success. There might be problems created or perceived by the other side of communcation. By using a Japanese approach, Americans could help their Japanese communication partners to understand and cope with Japanese problems. Then they might be able to enhance the possibility of successful communication between the two cultures.

A problem associated with the application of a Japanese approach is the assessment of the effectiveness of this approach. Research could be conducted to examine if the prescriptions of a Japanese approach to improving intercultural communication are really predictors of intercultural effectiveness as this approach suggests. First, those prescriptions would need to be defined operationally and measured. Each prescription could be considered to be either "verbal/cognitive competency" or 
"behavioral competency." The former could be measured by paper-andpencil instruments, and the latter, by "the systematic collection and analysis of an individual's behavior" (Ruben, 1976, pp. 336-337) .

Second, effectiveness of intercultural communication would need to be measured. This could be interpreted differently according to the particular intercultural setting of research. In a business context, it could mean success in an assigned task performed by two cultural groups. In an orientation program for students going overseas, it could be interpreted as their smooth adaptation to school life in a foreign culture.

Then, a correlational study could be conducted to see how each prescription relates to effectivenesss of intercultural communication. If the correlation is high, the prescription could be said to be valid. If many of the prescriptions have high correlation, then a Japanese approach could be said to be effective.

In such research, the differences between the Western approach and a Japanese approach would also need to be considered. In this paper, the goal of intercultural cammunication is defined as mutual understanding. As discussed in Chapter IV, the establishment of harmony in relationships seems to be an important part of mutual understanding in a Japanese approach. The relational aspect of communication would thus need to be more emphasized in defining the term "effectiveness in intercultural communication" in doing research.

There would be more things which would need careful consideration when doing research on a Japanese approach. It would be important to pay attention to any possibility of cultural differences. 
In this section, the application of a Japanese approach to intercultural communication has been discussed. This would be an important area of the field of intercultural comminication in Japan as it is in the United States. It is hoped that the modification of Western ideas in this field, which has been attempted in the previous chapters, will make the designs of intercultural training programs more suitable for Japanese. 


\section{BIBLIOGRAPHY}

Adler, Peter S. "Culture Shock and the cross Cultural Iearning Experience." In Readings in Intercultural Communications, Vol. 2. Edited by D. Hoopes. Pittsburgh: The Intercultural Communications Network, 1972.

- "Beyond Cultural Identity: Reflections on Cultural and Multicultural Man." In Intercultural Communication: A Reader, 3rd ed., pp. 389-406. Edited by L. A. Samovar, and R. E. Porter. Belmont, CA: Wadsworth, 1982 .

Asante, Molefi. "Intercultural Conmunication: An Inquiry into Research Directions." In Communication Yearbook 4, pp. 401-410. Edited by D. Nimo. New Brunswick, N.J.: The International Communication Association, 1980.

Asante, Molefi A.; Newmark, Eileen; and Blake, Cecil A. "The Field of Intercultural Communication." In Handbook of Intercultural Communication, pp. 11-22. Edited by M. A. Asante; E. Newmark; and C. A. Blake. Beverly Hills: Sage, 1979.

Barna, LaRay M. "Stumbling Blocks in Intercultural Communication." In Intercultural Communication: A Reader, 3rd ed., pp. 322-220. Edited by L. A. Samovar and R. E. Porter. Belmont, CA: Wadsworth, 1982.

Barnett, George A. and Kincaid, D. Lawrence. "Cultural Convergence: A Mathematical Theory." In International and Intercultural Conmunication Annual, Vol. VII, pp. 171-194. Edited by William B. Gudykunst. Beverly Hills: Sage, in cooperation with The Speech Conmunication Association, 1983.

Bamlund, Dean C. Public and Private Self in Japan and the United States. Tokyo, Japan: The Simul Press, 1975.

- "Communication in a Global Village." In Intercultural Communication: A Reader, 3rd ed., pp. 4-15. Edited by L. A. Samovar and R. E. Porter. Belmont, CA: Wadsworth, 1982.

Benedict, Ruth. The Chrysanthemum and the Sword. Boston: Houghton Mifflin Company, 1946.

Bennett, Milton J. "Empathic Perception: The Operation of Self-awareness in Human Perception." Unpublished masters thesis, Department of Speecis Communication, San Francisco State University, 1972. 
. "Overcoming the Golden Rule: Sympathy and Empathy."

In Communication Yearbook 3, pp. 407-422. Edited by D. Nimmo.

New Brunswick, N.J.: The International Communication Association, 1979.

Berlo, David K. The Process of Communication. New York: Holt, Rinehart \& Winston, 1960 .

Brembeck, Winson L. "The Development and Teaching of a college course in Intercultural communication." In Readings in Intercultural CommunCation, Vol. II, pp. 9-23. Edited by D. S. Hoopes. LaGrange Park, II: The Intercultural communications Network, 1977.

Brislin, Richard W. Cross-cultural Encounters: Face-to-Face Interaction. New York: Pergamon, 1981.

Brislin, Richard W.; Landis, Dan; and Brandt, Mary E. "Conceptualizations of Intercultural Behavior and Training." In Handbook of Intercultural Training, Vol. I, pp. 1-35. Edited by D. Landis, and R. W. Brislin. New York: Pergamon, 1983.

Burk, Jerry L. "Intercultural Communication Vistas: Description, Concept, and Theory." In International and Intercultural Communication Annual, Vol. II, pp. 30-39. New York: The Speech Communication Association, 1975.

- "The Effects of Ethnocentrism upon Intercultural Communication: Functional and Dysfunctional." In International and Intercultural Conmunication Annual, Vol. III, pp. 20-34. New York: The Speech Communication Association, 1976.

Cathcart, Dolores, and Cathcart, Robert. "Japanese Social Experience and Concept of Groups." In Intercultural Communication: A Reader, 3rd ed., pp. 120-127. Edited by L. A. Samovar and R. E. Porter. Belmont, CA: Wadsworth, 1982.

Christopher, Robert C. The Japanese Mind. New York: Linden Press, 1983.

Clark, G., and Takemura, Kenichi. Yuniikuna Nihonjin (Unique Japanese). Tokyo, Japan: Kodansha, 1979.

Clarke, Clifford H., and Hoopes, David S. "Goals and Leadership in the Intercultural Communication Workshop." In Reading in Intercultural Cammunication, Vol. I, pp. 60-67. Edited by D. S. Hoopes. Pittsburgh: The Intercultural Communications Network, 1975.

Condon, John C., and Yousef, Fathi S. An Introduction to Intercultural Communication. New York: Bobbs-Merrill, 1975. 
Doi, L. Takeo. "The Japanese Patterns of Cammunication and the Concept of Amae." In Intercultural Communication: A Reader, 3rd ed., pp. 218-222. Edited by L. A. Samovar and R. E. Porter. Belmont, CA: Wadsworth, 1982.

Folb, Edith. "Who's Got the Roam at the Top? Issues of Dominance and Nondominance in Intracultural Camunication." In Intercultural Communication: A Reader, 3rd ed., pp. 132-141. Belmont, CA: Wadsworth, 1982 .

Fuji Xerox, Education Business Dept. Ima Naze ICC no Jidai ka (Why Is It the Time for ICC Now?). (brochure) Tokyo, Japan: Fuji Xerox, 1985.

Gaw, Beverly A. "Processing Questions: An Aid to Campleting the Learning Cycle." In The Annual Handbook for Group Facilitators, pp. 147-153. Edited by J. W. Pfeiffer and J. Jones. San Diego: University Associates, 1979.

Guajykunst, William B., and Hammer, Mitchell R. "Basic Training Design: Approaches to Intercultural Training." In Hanäbook of Intercultural Training, Vol. I, pp. 118-153. Edited by D. Landis, and R. W. Brislin. New York: Pergamon, 1983.

Hall, Edward T. Beyond Culture. Garden City, N.J.: Anchor Press, 1976; Anchor Books, 1977.

Hamaguchi, Eshun. "Nihon Rashisa" no Sai-hakken (Re-discovery of Japaneseness) . Tokyo, Japan: Nihon Keizai Shinbunsha, 1977.

- "Nihonteki Shudan Shugi towa Nani ka" (What is Japanese Groupism? In Nihonteki Shudan Shugi (Japanese Groupism), pp. 1-26. Edited by E. Hamaguchi and S. Kumon. Tokyo, Japan: Yuikaku, 1982.

Harms, L. S. Intercultural Cammunication. îNew York: Harper \& Row, 1973.

Harper, Nancy. Human Communication Theory: The History of a Paradigm. Rochelle Park, N.J.: Hayden Book, 1979.

Harris, Phillip R., and Moran, Robert T. "Understanöing Cultural Differences." In Intercultural Communication: A Reader, 3rd ed., pp. 62-72. Belmont, CA: Wadsworth, 1982.

Hayashi, C. "Hihonjin no Tai-gaikoku-bunka-taido to Tai-gaikokujin-taido" (The Japanese Attitudes ioward Foreign Cultures and Foreign People). In Nihon Kenkyu (Study of Japan), pp. 191-198. Tokyo, Japan: Shiseido, 1977.

Hoopes, David S. "Intercultural Communication Concepts and the Psychology of Intercultural Experience." In Multicultural Education: A Cross Cultural Training Approach, pp. 10-38. Edited by M. D. Pusch. Chicago: Intercultural Network, 1979.

Hoopes, David S., and Pusch, Margaret D. "Definition of Terms." In Multicultural Education: A Cross Cultural Training Approach, pp. 2-8. Edited by M. D. Pusch. Chicago: Intercultural Network, 1979. 
Hori, H. "Hihonjin no Gaikoku Hyoka to sono Tokucho" (Japanese Evaluation of Foreign Countries and Characteristics). In Nihonjin Kenkyu (Study of Japan), pp. 81-129. Tokyo, Japan: Shiseido, 1977.

Howell, William S. "Can Intercultural Communication be Taught in a Classroam?" In Readings in Intercultural Communication, Vol. II, pp. 3-8. Edited by D. S. Hoopes. LaGrange, II: The Intercultural Conmunications Network, 1977.

Inamura, Hiroshi. Nihonjin no Kaigai Futekio (The Maladjustment of Japanese to Foreign Countries). Tokyo, Japan: Nihon Hoso Shuppan Kyokai, 1980.

Jensen, J. Vernon. "Perspective on Nonverbal Intercultural Commuication." In Intercultural Communication: A Reader, 3rd ed., pp. 260-276. Edited by L. A. Samovar and R. E. Porter. Belmont, CA: Wadsworth, 1982.

Kano, Tsutomu. "Why the Search for Identity?" In The Silent Power, pp. 1-10. Edited by Japan Center for International Exchange. Tokyo, Japan: Simul Press, 1976.

Kawashima, Takeyoshi. "The Status of the Individual in the Notion of Law, Right, and Social Order in Japan." In The Japanese Mind: Essentials of Japanese Philosophy and Culture, pp. 262-287. Edited by C. A. Moore. Honolulu: East-West Center Press, 1967.

Kim, Young Yun. "Searching for Creative Integration." In International and Intercultural Communication Annual, Vol. VIII, pp. 13-30. Edited by W. B. Gudykunst and Y. Y. Kim. Beverly Hills: Sage, in cooperation with The Speech Conmunication Association, 1984.

Kimura, Bin. Hito to Hito to no Aida (The Space Between People). Tokyo, Japan: Kobundo, 1972.

Kishimoto, Hideo. "Same Japanese Cultural Traits and Religions." In The Japanese Mind: Essentials of Japanese Philosophy and Culture, pp. 110-121. Edited by C. A. Moore. Honolulu: East-West Center Press, 1967.

Kluckhohn, Florence Rockwood, and Strodtbeck, Fred L. Variations in Value Orientations. Elmsford, N.Y.: Row Peterson and Company, 1961.

Lebra, Takie Sugiyama. Japanese Patterns of Behavior. Honolulu: East-West Center, University of Hawaii Press, 1976.

Lum, John. "Marginality and Multiculturalism: Another Look at Bilingual/ Bicultural Education." In Intercultural Communication: A Reader, 3rd ed., pp. 384-388. Edited by L. A. Samovar and R. E. Porter. Belmont, CA: Wadsworth, 1982. 
Mestenhauser, Josef A. "In Search of Common Variables and Interests in Cross-cultural Research in Japan." Unpublished paper, 1981.

Mori, Joji. Nihonjin-"Karanashi Tamago" no Jigazo (The Japanese-Self Portrait of "An Egg Without a Shell"). Tokyo, Japan: Kodansha, 1977.

Morsbach, Helmut. "Aspects of Nonverbal Cammication in Japan." In Intercultural Communication: A Reader, 3rd ed., pp. 300-316. Edited by L. A. Samovar and R. E. Porter. Belmont, CA: Wadsworth, 1982 .

Nakamura, Hajime. Ways of Thinking in Eastern Peoples: India, China, Tibet, Japan. Honolulu: East-West Center Press, 1964 .

Nakane, Chie. Tekio no Joken (Conditions for Adjustment). Tokyo, Japan: Kodansha, 1972.

- Tate-shakai no Rikigaku (Dynamics of Vertical Society). Tokyo, Japan: Kodansha, 1978.

Nakano, Osamu. "Nihon-gata Soshiki ni okeru Kominikeishon to Ishi-kettei" (Communication and Decision-making in Japanese-style Organizations). In Nihon-teki Shudan-shugi (Japanese Groupism), pp. 143-168. Edited by E. Hamaguchi and S. Kumon. Tokyo, Japan: Yuikaku, 1982.

Naotsuka, Reiko, and Sakamoto, Nancy. Mutual Understanding of Different Cultures. Osaka, Japan: Science Ecucation Institute of Osaka Prefecture, 1981.

Nasu, Kiyoshi. Kuzureyuku Nichibei Kankei (Declining U.S.-Japan Relations). Tokyo, Japan: Takai Shoho, 1978. Quoted in Jared Taylor, Shadow of the Rising Sun, p. 52. New York: William Morrow and Company, 1983.

Newmark, Eileen, and Asante, Molefi K. "Perception of Self and Others: An Approach to Intercultural Communication." In International and Intercultural Communication Annual, Vol. II, pp. 54-61. New York: The Speech Communication Association, 1975.

Northrop, F. S. C. The Meeting of East and West. New York: Macmillan, 1946; Collier Books, 1966.

Okabe, Roichi. "Cultural Assumptions of East and West: Japan and the United States." In International and Intercultural Cammunication Annual, Vol. VII, pp. 21-44. Edited by W. B. Gudykunst. Beverly Hills: Sage, sponsored by the Speech Communication Association, 1983.

Oshio, Takashi. "Communicating with the West." In Japan Echo, Vol. IX, No. 3, pp. 105-113. Tokyo, Japan: Japan Echo, 1982 . 
Peterson, Richard B., and Shimada, Justin Y. "Sources of Management Problems in Japanese-American Joint Ventures." In Acadeny of Management Review, October 1978, pp. 796-804.

Porter, Richard E., and Samovar, Larry A. "Approaching Intercultural Communication." In Intercultural Communication: A Reader, 3rd ed., pp. 26-42. Edited by L. A. Samovar and R. E. Porter. Belmont, CA: Wadsworth, 1982.

Prosser, Michael H. The Cultural Dialogue: An Introduction to Intercultural Conmunication. Boston: Houghton Mifflin, 1978.

Ramsey, Sheila, and Birk, Judy. "Preparation of North Americans for Interaction with Japanese: Considerations of Language and Communication Style." In Handbook of Intercultural 'Training. Vol. III, pp. 227-259. Edited by D. Landis and R. W. Brislin. New York: Pergamon, 1983.

Reischauer, Edwin O. The Japanese. Tokyo, Japan: Charles E. Tuttle, 1978.

Rogers, Everett M., and Kincaid, D. Lawrence. Communication Networks: Toward a New Paradigm for Research. New York: Macmillan, 1981.

Ruben, Brent D. "Assessing Communication Competency for Intercultural Adaptation." In Group \& Organization Studies, September 1976, $I(3)$, pp. 334-354.

- "Human Cormunication and Cross-Cultural Effectiveness." In Intercultural Communication: A Reader, 3rd ed., pp. 331-339. Edited by L. A. Samovar and R. E. Porter. Belmont, CA: Wadsworth, 1982 .

Ruhly, Sharon. "Orientations to Intercultural Communication." In Modcom, pp. 3-33. Edited by R. L. Applbaum and R. P. Hart. Chicago: Science Research Associates, 1976.

Sakamaki, Sinunzo. "Shinto: Japanese Ethnocentrism." In The Japanese Mind: Essentials of Japanese Philosophy and Culture, pp. 24-32. Edited by C. A. Moore. Honolulu: East-West center, 1967.

Samovar, Larry A. "Ecucational objectives in Intercultural Communication: Some Variations on an Old and Tired Theme." In Intercultural Theory and Practice. Edited by W. G. Davey. LaGrange Park, IL: Intercultural Network, 1979.

Samovar, Larry A.; Porter, Richard E.; and Jain, Nemi C. Understanding Intercultural Communication. Belmont, CA: Wadsworth, 1981.

Saral, Tulsi B. "Intercultural Cormunication Theory and Research: An Overview." In Conmunication Yearbook 1, pp. 389-396. Edited by B. D. Ruben. New Brunswick, N.J.: The International Cormunication Association, 1977. 
- "Intercultural Communication Theory and Research: An Overview of Challenges and opportunities." In Cammication Yearbook 3, pp. 395-405. Edited by D. Nimmo. New Brunswick, N.J.: The International Communication Association, 1979.

- "The Conscious Theory of Intercultural Cammunication." In Handbook of Intercultural Communication, pp. 79-84. Edited by M. A. Asante, E. Newmark and C. A. Blake. Beverly Hills: Sage, 1979.

Sarbaugh, L. E. Intercultural Communication. Rochelle Park, N.J.: Hayajen Book, 1979 .

Scalzi, Dante V., and Spring, Cornelia. "Value of the Intercultural Cammunication Workshop on Campus." In Readings in Intercultural Cammunication, Vol. I, pp. 54-59. Edited by D. Hoopes. Pittsburgh: The Intercultural Communications Network, 1975.

Shirts, Gary. BAFA BAFA (Simulation Game). Del Mar, CA: Simile II, 1973.

Singer, Marshall R. "Culture: A Perceptual Approach." In Intercultural Communication: A Reader, 3rd ed., pp. 54-61. Edited by L. A. Samovar and R. E. Porter. Belmont, CA: Wadsworth, 1982.

Stewart, Eơward C. American Cultural Patterns: A Cross-cultural Perspective. Chicago: Intercultural Press, 1972.

- "Outline of Intercultural cormunication." In International and Intercultural Communication, pp. 265-331. Edit-d by F. Casmir. Washington: University Press of America, 1978.

- "Applications of Intercultural Communication in Japan." Speech presented at 3rd study meeting of the Kanto chapter of the Communication Association of the Pacific, conducted at Showa University, Tokyo, December 13, 1980.

Sumner, William Graham. Folkways. Boston: Ginn and Company, 1906.

Suzuki, Takao. "Nihongo no Jishoshi to Tashoshi." In Gendai no Esupuri: Nihonjin no Aidagara, pp. 121-126. Edited by E. Hamaguchi, Tokyo, Japan: Shibundo, 1982 .

Szalay, Ioran̄ B. "Adapting Communication Research to the Needs of International and Intercultural Communications. In International and Intercultural Communication Annual, Vol. I, pp. 1-16. Beverly Fills: The Speech Communication Association, 1974.

Taylor, Jared. Shadows of the Rising Sun: A Critical View of the "Japanese Miracle." New York: William Morrow, 1983. 
Triandis, Harry C. The Analysis of Subjective Culture. New York: John Wiley \& Sons, 1972 .

Tsurumi, Kazuko. Kokishin to Nihonjin (Curiosity and the Japanese). Tokyo, Japan: Kodansha, 1972.

Tucker, Raymond K., Weaver, Richard L. II, and Berryman-Fink, Cynthia. Research in Speech Comminication. Englewood Cliffs, N.J.: PrenticeHall, 1981.

Turner, Jonathan $\mathrm{H}$. The Structure of Sociological Theory, 3rd ed. Homewood, II: The Dorsey Press, 1982.

Umesao, Tadao. "Escape from Cultural Isolation." In The Silent Power, pp. 13-34. Edited by Japan Center for International Exchange. Tokyo, Japan: Simul Press, 1976.

Wagatsuma, Hiroshi. "Shudan-shugi no Shinri-teki Yoin." (Psychological Factors of Groupism). In Nihon-teki Shudan-shugi (Japanese Groupism), pp. 47-74. Edited by E. Hamaguchi. Tokyo, Japan: Yuikaku, 1982.

Watzlawick, Paul;:Beavin, Janet Helmick; and Jackson, Don D. Pragmatics of Human Conmunication. New York: W. W. Norton, 1967. 